article is available as 'Online First':

http://link.springer.com/article/10.1007/s00271-017-0562-8

\title{
Growth and water relations of field-grown 'Valencia' orange trees under long-term partial rootzone drying
}

Amr Mossad ${ }^{2,3}$, Alessio Scalisi $^{1}$, Riccardo Lo Bianco $^{1 *}$

${ }^{1}$ Department of Agricultural, Food and Forest Sciences, University of Palermo, Viale delle Scienze, 90128 Palermo, Italy.

${ }^{2}$ Agricultural Engineering Department, King Saud University, Riyadh 11451, Kingdom of Saudi Arabia.

${ }^{3}$ Agricultural Engineering Department, Ain Shams University, Cairo 11241, Egypt.

* Corresponding author email: riccardo.lobianco@unipa.it

Tel.: +39-091-23896097

ORC-ID: 0000-0003-2568-2880 


\begin{abstract}
Climate, soil water potential (SWP), leaf relative water content (RWC), stem water potential (WP $\mathrm{Stem}_{\text {), }}$ stomatal conductance $\left(g_{s}\right)$, trunk, shoot and fruit growth of 'Valencia' orange trees were monitored during five consecutive seasons (2007-2012) to study water status and growth responses to irrigation placement or volume. Forty-eight adult trees were exposed to conventional irrigation (CI, $100 \%$ of crop evapotranspiration on both sides of the rootzone), partial rootzone drying (PRD, 50\% of CI water only on one alternated side of the rootzone) and continuous deficit irrigation (DI, $50 \%$ of CI water on both sides of the rootzone). Reducing irrigation volumes by 55\% (DI) over CI increased leaf water deficit by $27 \%$ and reduced 'Valencia' fruit growth by $15 \%$ but not shoot or trunk growth. Similar water savings by PRD did not induce significant growth reductions. Differences in fruit growth rates determined a $17 \%$ yield reduction in DI but not PRD trees. If we consider integrals of data across each season, PRD induced milder soil and leaf water deficit than DI but similar stomatal conductance. Tree daily water consumption $\left(E_{\text {tree }}\right)$ estimated from daily leaf transpiration was significantly lower in PRD and DI than in CI. Fruit growth efficiency (growth rate per unit $E_{\text {tree }}$ ) was similar in all irrigation treatments, while shoot growth efficiency was higher in PRD than in CI. In PRD, an increased shoot growth efficiency rather than fruit growth efficiency is most likely due to water and assimilates being diverted from fruit to shoot growth under high VPD conditions. Although these results show good evidence of an irrigation placement effect inducing an advantage of the PRD strategy in 'Valencia' orange in terms of milder soil and leaf water deficit and more sustainable fruit growth compared to DI, PRD did not induce any significant advantage in terms of final yield over a simple reduction of irrigation volumes.
\end{abstract}

\title{
Introduction
}

Cultivation of fruit trees in semi-arid regions is often characterized by increased evapotranspiration, high soil salinity and limited water availability. Those conditions are expected to spread and intensify, especially in the Mediterranean, due to climatic changes, demographic pressure and greater allocation of water resources to municipalities and touristic areas. For those reasons increasing crop water use efficiency through the rationalization of irrigation becomes critical also for citrus fruit production.

Regulated deficit irrigation (RDI) has been long recognized as a potent tool to manage fruit trees, and specifically to reduce shoot growth, improve fruit quality, and save some irrigation water by imposing moderate levels of plant water stress (Chalmers et al. 1981; Mitchell and Chalmers 1982). Results of RDI experiments have been promising in certain regions and for some fruit crops, such as peach (Chalmers et al. 1981), pear (Pyrus communis L.) (Mitchell et al. 1989; Caspari et al. 1994), French prune (Prunus domestica L.) (Lampinen et al. 1995), almond (Prunus dulcis L.) (Goldhamer et al. 2006), pistachio (Pistacia vera L.) (Goldhamer and Beede 2004), apricot (Prunus armeniaca L.) (Ruiz-Sáncez et al. 2000), and olive (Olea europaea L.) (Moriana et al. 2003; Marino et al. 2016; Marra et al. 2016). In citrus, where yield seems to be proportional to shoot growth, the control and regulation of water deficit is quite complex resulting often in significant fruit drop or reduced final fruit size and yields, depending on the period of deficit imposition (González-Altozano and Castel 1999; Pérez-Pérez et al. 2008; Hutton and Loveys 2011). Other long-term RDI studies have reported increased water use efficiency in orange (Garcia-Tejero et al., 2011; Gasque et al., 2016) and improved fruit quality in 'Clementina de Nules' (Ballester et al., 2014).

Partial rootzone drying (PRD) is an irrigation technique where only one half of the rootzone is irrigated, whereas the other half is not, and it was originally developed for grapes (Vitis vinifera L.) in Australia, with the primary aim of saving irrigation water (Dry et al. 1995; Dry and Loveys 1998). The physiological basis for PRD is that roots in drying soil produce abscisic acid (ABA), which is translocated to the shoots where it signals a developing soil-water deficit (Dry et al. 1995). In the leaves, ABA induces partial stomatal closure, which reduces transpiration and may increase water use efficiency. However, as the other half of the rootzone is kept well watered, the effect on plant water 
potential is minimal (Gowing et al. 1990) and other metabolic and physiological processes associated to water stress are not affected (Dry et al. 1995; Dry et al. 2000). The technique relies on cyclical wetting and drying of parts of the rootzone in order to maintain root derived ABA signals (Zhang and Davies 1987). Increased xylem ABA and $\mathrm{pH}$ (Davies et al. 2002), both probably responsible for partial stomatal closure, and reductions of cytokinin levels in roots, shoot apexes, and buds (Stoll et al. 2000) have been reported in plants under PRD regime. The resulting changes in hormonal balance may contribute to reduce vegetative growth under those conditions.

The impact of PRD has been extensively investigated in grapevine (Dry and Loveys 1998, 1999; Dry et al. 2000; Stoll et al. 2000) and, to a lesser extent, in other woody perennials (e.g. olive, Wahbi et al. 2005; apple, Lo Bianco and Francaviglia 2012; Francaviglia et al. 2013). Many studies support a PRD effect (e.g. grapevines, Antolín et al., 2006; apple, Leib et al. 2006; mango, Spreer et al. 2007), but some studies support a water volume effect (e.g. grapevines, Marsal et al., 2008; Sadras, 2009).

The data available on citrus have pointed to a water deficit effect on yield and fruit size (Eliades et al. 2004), whereas contrasting results were obtained in response to PRD, mainly depending on different citrus species and varieties. In sub-tropical evergreen citrus trees, vegetative growth is often positively related to yield, and drought stress almost always results in reductions in growth and yield (Syvertsen 1985). Thus, large amounts of irrigation water are generally supplied to citrus trees to prevent drought stress and yield losses. Water savings by DI and PRD in citrus have not been entirely successful in Navel oranges (Citrus sinensis), where tree growth, fruit size and yield decreased in response to insufficient amounts of water (Treeby et al. 2007; Hutton and Loveys 2011; Faber and Lovatt 2014). On the contrary, yields and crop loads were maintained to control levels in other PRD works with orange, grapefruit (Citrus paradisi) and lemon (Citrus lemon) (Goldhamer and Salinas 2000; Pérez-Pérez et al. 2012; Kusakabe et al. 2016; Consoli et al. 2017).

However, the use of PRD in citrus trees has not been extensively investigated as there is scarce information on growth responses to long-term deficit irrigation. The objective of the present study was to determine water status and growth responses of 'Valencia' orange trees to irrigation placement or volume effects determined by five consecutive seasons of PRD and continuous water deficit.

\section{Materials and methods}

Experimental site and plant material

The experiment was performed in an experimental plot of the Department of Agricultural, Food and Forest Sciences, University of Palermo, Italy $(30.06 \mathrm{~N}, 13.21 \mathrm{E}$, and $31 \mathrm{~m}$ a.s.1.). The soil was a loam ( $52 \%$ sand, $29.1 \%$ silt, and $18.9 \%$ clay) with $0.239 \mathrm{~m}^{3} \mathrm{~m}^{-3}$ water content and $-12.9 \mathrm{kPa}$ water potential at field capacity (FC).

The study was carried out using 48 32-year-old orange trees (Citrus sinensis, cv Valencia) grafted onto sour orange (Citrus aurantium, L.) rootstock, spaced at $4 \times 4 \mathrm{~m}$, trained to raised globe canopy starting at about $0.8 \mathrm{~m}$ from the ground and reaching $2.5-3 \mathrm{~m}$ in height. The study considered five crop seasons starting in spring 2007 and ending with the harvest of the fifth crop in spring 2012. Typically, the 'Valencia' orange trees at the experimental site bloom in the month of April and mature fruits after about 400 days.

Except for irrigation, all trees received the same conventional cultural cares. Complex solid fertilizers $(11 \mathrm{~N}: 22 \mathrm{P}: 16 \mathrm{~K}$ at the rate of $1.5 \mathrm{~kg} /$ tree $)$ were applied to the soil once a year in winter and weeds were controlled by regular tilling of inter-rows and rows. For the entire tree life, irrigation was provided by a micro-sprinkler system with a single line per tree row and two emitters per tree located at about $1 \mathrm{~m}$ from the trunk and $0.5 \mathrm{~m}$ above the ground. For this experiment, micro-sprinklers with $360^{\circ}$ circular spray pattern and nominal delivery rates at 1 bar of $183 \mathrm{~L} \mathrm{~h}^{-1}\left(2-\mathrm{mm}\right.$ diam) and $386 \mathrm{~L} \mathrm{~h}^{-1}$ (3$\mathrm{mm}$ diam) were used. Micro-sprinklers were connected to PVC laterals (one per tree row) with 5-mm 
diameter polyethylene tubing of various length and wood sticks were used for exact positioning of emitters with respect to tree trunk $(1 \mathrm{~m})$, soil humidity sensors $(80 \mathrm{~cm})$, and portion of rootzone to be irrigated. In PRD, one emitter per tree was connected to the lateral and moved from one (wet) side to the opposite (dry). Overlapping of wetted areas was carefully avoided.

Before the irrigation season started each year, the system was flushed to clean various deposits out of the pipes and micro-sprinklers. Uniformity of water distribution was checked by measuring delivery rates of all emitters each year before and during the irrigation season.

Irrigation treatments and experimental design

In spring 2007, 48 trees uniform in size were selected and labeled according to a randomized block design with four replicates (blocks), each including four trees per irrigation treatment (total 12 trees per replicate). Two consecutive trees on the row and one entire tree row were used as guard trees between irrigation treatments. In June, three irrigation treatments were imposed, 1) conventional irrigation (CI), where two 3-mm-diameter emitters per tree were used so that trees received $100 \%$ of water consumed by crop evapotranspiration on both sides of the rootzone; 2) partial rootzone drying (PRD), where one 3-mm-diameter emitter per tree was used so that trees received about $50 \%$ of CI water only on one alternated side of the rootzone; 3) continuous deficit irrigation (DI), where two 2mm-diameter emitters per tree were used so that trees received about $50 \%$ of CI water on both sides of the rootzone. The interval between irrigation events and the duration of each event (minimum $40 \mathrm{~min}$, maximum $2 \mathrm{~h}$ ) were adjusted to maintain soil moisture of wetted volume above $80 \%$ of field capacity ($50 \mathrm{kPa}$ ) in the rootzone of CI trees but avoid spreading of wet areas into the dry sides of PRD trees. Wet and dry sides of PRD trees were alternated every 2-3 weeks when soil water potential in the dry side reached approximately $-150 \mathrm{kPa}$.

Climate, water requirements, and water status

Climate parameters were recorded hourly with two $\mu$ Metos weather stations (Pessl Instruments, Austria) positioned within the experimental plot equipped with temperature, relative humidity and light sensors and a rain gauge. Local data were compared to regional agro-meteorological data (Servizio Informativo Agrometeorologico Siciliano) from a nearby station and used to calculate daily reference evapotranspiration ( $\left.\mathrm{ET}_{0}\right)$ according to the FAO Penman-Monteith equation. Irrigation volumes to $\mathrm{CI}$ trees were calculated to meet crop evapotranspiration $\left(\mathrm{ET}_{\mathrm{c}}\right)$, which was determined as:

$$
\mathrm{ET}_{\mathrm{c}}=\mathrm{ET}_{0} \times \mathrm{K}_{\mathrm{c}}
$$

where $\mathrm{K}_{\mathrm{c}}$ was derived from FAO indications and set to 0.7 from October through May, and to 0.65 from June through September, due to the specific soil management, climate conditions and to the fact that 'Valencia' trees bear fruits all year around (Allen et al. 1998).

Vapor pressure deficit (VPD, $\mathrm{kPa}$ ) was calculated from air temperature (in ${ }^{\circ} \mathrm{C}$ ) and relative humidity (in \%) measured hourly at the experimental site, and plotted against time to give an indication of daily variation in atmospheric vapor demand at sampling dates. In addition, instantaneous VPD was calculated from canopy air temperature and relative humidity measured on the same dates and time as stomatal conductance, and used to establish associations with other parameters. Soil water potential (SWP) was monitored continuously at a fixed depth of $45 \mathrm{~cm}$ with Watermark sensors (Irrometer Co., Riverside, CA, USA) directly connected to the weather station. Twelve sensors were positioned at about $80 \mathrm{~cm}$ from emitters and $1 \mathrm{~m}$ from the tree trunk in opposite sides of the rootzone. The integral of soil water deficit (SWD int) for each irrigation season and treatment was calculated as: 


$$
\mathrm{SWD}_{\text {int }}=\Sigma_{(1 . . \mathrm{t})}\left(\mathrm{SWP}_{\mathrm{i}}-\mathrm{SWP}_{\mathrm{FC}}\right)
$$

where $t$ is the number of days in the irrigation season, $\mathrm{SWP}_{\mathrm{i}}$ are average daily measures of soil water potential, and SWP $\mathrm{FC}_{\mathrm{C}}$ is soil water potential at field capacity. SWD int was used as an indication of soil water deficit accumulated in the root-zone of each treatment during the irrigation periods.

Bi-weekly throughout the irrigation period and at longer intervals during rainy periods, one mature leaf per tree was wrapped in parafilm and aluminum foil, detached, enclosed in zip-lock bags, and transported in ice to the laboratory for determination of fresh weight (FW). Leaf samples were rehydrated for $24 \mathrm{~h}$ in the dark at $8{ }^{\circ} \mathrm{C}$ for determination of turgid weight (TW) and subsequently oven dried at $60{ }^{\circ} \mathrm{C}$ to constant weight for determination of dry weight (DW). Leaf relative water content (RWC) was calculated as:

$$
\mathrm{RWC}=[(\mathrm{FW}-\mathrm{DW}) /(\mathrm{TW}-\mathrm{DW})] \times 100 .
$$

Leaf water saturation deficit (LWSD) was calculated as $1-(\mathrm{RWC} / 100)$ and the integral across each irrigation period was estimated using the equation proposed by García-Tejero et al. (2010) and modified from Myers (1988):

$$
\mathrm{LWSD}_{\text {int }}=\Sigma_{(1 . . \mathrm{t})}\left|\mathrm{LWSD}_{\mathrm{i}+1} \times\left(\mathrm{n}_{\mathrm{i}+1}-\mathrm{n}_{\mathrm{i}}\right)+1 / 2\left(\mathrm{LWSD}_{\mathrm{i}}-\mathrm{LWSD}_{\mathrm{i}+1}\right) \times\left(\mathrm{n}_{\mathrm{i}+1}-\mathrm{n}_{\mathrm{i}}\right)\right|
$$

where $t$ is the number of sampling days, $\mathrm{LWSD}_{\mathrm{i}}$ and $\mathrm{LWSD}_{\mathrm{i}+1}$ are leaf water deficit values measured on two consecutive sampling days ( $i$ and $i+1)$, and $n_{i+1}$ and $n_{i}$ the days corresponding to two serial samplings. LWSD int was used as an indication of water deficit accumulated by trees during the irrigation period in each year of study.

In the same sampling dates, one leaf similar to those used for RWC measurements was selected and stomatal conductance $\left(g_{s}\right)$ was measured with an AP4 Delta-T dynamic porometer (Delta-T Devices, Cambridge, UK). On each date, the device was calibrated and $g_{s}$ was measured between 10:00HR and 12:00HR on one mature, sun-exposed leaf per tree. The integral of stomatal conductance was also calculated as:

$$
\mathrm{Gs}_{\text {int }}=\Sigma_{(1 . . t)}\left|\mathrm{g}_{\mathrm{i}+1} \times\left(\mathrm{n}_{\mathrm{i}+1}-\mathrm{n}_{\mathrm{i}}\right)+1 / 2\left(\mathrm{~g}_{\mathrm{i}}-\mathrm{g}_{\mathrm{i}+1}\right) \times\left(\mathrm{n}_{\mathrm{i}+1}-\mathrm{n}_{\mathrm{i}}\right)\right|
$$

where $t$ is the number of sampling days, $g_{i}$ and $g_{i+1}$ are leaf stomatal conductance values measured on two consecutive sampling days ( $i$ and $i+1)$, and $n_{i+1}$ and $n_{i}$ the days corresponding to two serial measurements. In this case, Gsint was used as an indication of the stomatal conductance accumulated by trees during the irrigation period in each year of study.

Leaf transpiration $(E)$ was derived from $g_{s}$ and VPD measurements and used to estimate tree daily water consumption $\left(E_{\text {tree }}, \mathrm{L}_{\text {day }}{ }^{-1}\right)$ assuming a leaf area index of 4 , a canopy projection area of $14.4 \mathrm{~m}^{2}$, and an average leaf area per tree of $57.8 \mathrm{~m}^{2}$.

Daily trends of RWC and $g_{s}$ were constructed at the beginning of the experiment taking measurements from 7.00 am until $7.30 \mathrm{pm}$ at intervals of about $1 \mathrm{hr}$. Measurements were taken on a mature leaf per tree, four trees per treatment (one tree per block). The porometer was calibrated three times during the day, early morning, midday and late afternoon.

On 1 June, 17 July, 6 and 29 August 2011, stem water potential ( $\mathrm{WP}_{\text {stem }}$ ) was measured in four trees per irrigation treatment. Selected leaves were wrapped in parafilm and aluminum foil and after 1 $\mathrm{hr}, \mathrm{WP}_{\text {stem }}$ was determined using a 1505D PMS pressure chamber (PMS Instrument Company, Albany, OR, USA). The same leaves were transported in ice to the laboratory and RWC was determined as described above. Measurements of $\mathrm{WP}_{\text {stem }}$ were also taken on rehydrated leaves and data were used to establish a relationship between RWC and $\mathrm{WP}_{\text {stem. }}$. 
Growth measurements

In all five years and on the same dates as previous measurements, height and width of one fruit per tree were measured with a digital caliper and used to calculate changes in average diameters and fruit relative growth rate $\left(\mathrm{RGR}_{\text {fruit }}\right)$ in $\mathrm{mm} \mathrm{mm}^{-1}$ day $^{-1}$. Concurrently, also a growing shoot per tree was selected, labeled and measured. Shoot relative elongation rate $\left(\mathrm{RGR}_{\text {shoot }}\right)$ was calculated and expressed as $\mathrm{mm} \mathrm{mm}^{-1}$ day $^{-1}$. Similar fruits and shoots were selected from the same side/height of the canopy in all trees in trial. Trunk circumference was also measured above the graft union each year before harvest and trunk growth was estimated as the increase in trunk cross-sectional area (TCSA) from harvest 2008 to harvest 2012 normalized by the initial TCSA divided by the number of years $\left(\mathrm{cm}^{2} \mathrm{~cm}^{-2}\right.$ year-1). Fruit growth rate efficiency $\left(\mathrm{GRE}_{\text {fruit }}\right)$ and shoot growth rate efficiency $\left(\mathrm{GRE}_{\text {shoot }}\right)$ were calculated dividing $\mathrm{RGR}_{\text {fruit }}$ and $\mathrm{RGR}_{\text {shoot }}$ by $E_{\text {tree }}$ and expressed as $\mathrm{mm} \mathrm{mm}^{-1} \mathrm{~m}^{-3}$. Those two measurements are estimates of water use efficiency in terms of growth at a whole tree scale and are determined to study the partitioning of water use toward shoot vs fruit growth.

Data analysis

Trunk growth rates over the five years were tested by one-way analysis of variance with irrigation treatment as the main factor, and block as replicate factor. Daily changes of $\mathrm{WP}_{\text {stem, }}, g_{s}$, and transpiration were tested by two-way analysis of variance with irrigation treatment and time as the two main factors and irrigation $x$ time as the sole interaction. $\mathrm{LWSD}_{\text {int }}$ and $\mathrm{Gs}_{\text {int }}, E_{\text {tree }}, \mathrm{RGR}_{\text {fruit }}, \mathrm{RGR}_{\text {shoot, }}$ $\mathrm{GRE}_{\text {fruit }}$ and $\mathrm{GRE}_{\text {shoot }}$ were tested by two-way analysis of variance with irrigation treatment and year as main factors, block as replicate factor, and irrigation $\mathrm{x}$ year as the sole interaction. Seasonal changes of $\mathrm{RWC}, g_{s}$ and fruit diameter across sampling dates of each year were tested by repeated measure analysis of variance with irrigation treatment as the between-subject main factor, block as a betweensubject replicate factor, sampling dates as the within-subject factor and sampling dates $\mathrm{x}$ irrigation as the sole interaction. When appropriate, means were compared using Tukey's multiple range test $(P<$ 0.05). Least squares regression analysis and Pearson's product moment correlation were used to establish relationships among RWC, $g_{s}$, SWP, $\mathrm{WP}_{\text {stem }}$, and VPD. Multiple linear regression analysis was used to detect variables that could help predict shoot or fruit seasonal growth (i.e. shoot length or fruit size increment over each irrigation season). All described statistical tests were performed using SYSTAT and Sigmaplot procedures (Systat Software Inc., Richmond, Ca., USA).

\section{Results}

Average fruit load across the years of trial was about 207 fruit/tree and did not differ among irrigation treatments $(\mathrm{P}=0.368)$. During the five years of trial, trees exhibited the typical alternate bearing of 'Valencia' orange with fruit load ranging from 77 to 325 fruit/tree and 2009 and 2011 as offyears. Only DI (26.3 kg/tree), not PRD (27.4 kg/tree), significantly reduced yields by $17 \%$ over CI $(31.8 \mathrm{~kg} /$ tree, $\mathrm{P}=0.045)$.

Climate, irrigation volumes and soil moisture

In all years, $\mathrm{ET}_{\mathrm{c}}$ was typically highest during the dry season, in summer, and lowest in winter (Tab. 1). Rainfall was mainly concentrated in fall and winter. Rainfall of 2009 was by far the greatest, although $30 \%$ of the annual rainfall was concentrated in winter, a lot before the irrigation season started, and over 50\% in fall, after the irrigation season was over. Due to scarce spring rainfall in 2008, 2010 and 2011 (Tab. 1), irrigation events started a few days earlier compared to 2007 and 2009 (Tab. 2). Relevant precipitations resumed earlier and the irrigation season was a few days shorter in 2009 and 
2010 compared to 2007, 2008 and 2011 (Tab. 2). In all years, irrigation volumes applied to CI trees fully satisfied summer ETc (Tab. 2), whereas spring atmospheric water deficit was mostly compensated by soil water accumulated during winter.

In all years, SWP of CI treatment showed fluctuations due to wetting and drying cycles between consecutive irrigation events, but staying generally above $-50 \mathrm{kPa}$ (about $80 \%$ of field capacity) during the irrigation period (Fig. 1). Only in a few cases, at the end of August in 2007 (Fig. 1A) and in midJuly in 2008 (Fig. 1B), SWP reached minimum values of -70 to $-80 \mathrm{kPa}$. In DI trees, SWP followed sharper fluctuations than in CI trees reaching minimum values of -160 to $-180 \mathrm{kPa}$ in late August 2007 (Fig. 1A), of $-160 \mathrm{kPa}$ often throughout July and August 2008 (Fig. 1B), of -190 to $-200 \mathrm{kPa}$ at the end of June, mid-July and mid-August 2009 (Fig. 1C), of -180 to -200 kPa in early August 2010 (Fig. 1D), and of $-140 \mathrm{kPa}$ in mid-August 2011 (Fig. 1E). In all five years, average SWP of wet and dry sides of PRD was lower than SWP of CI, but generally somewhat higher than SWP of DI. In 2007, wet and dry sides of PRD trees were alternated on 27 July, 14 August, and 4 September; in 2008, on 11 and 29 July, 17 August, and 11 September; in 2009, on 10 and 20 July, 2 and 13 August, and 7 September; in 2010, on 7 and 21 July, and 4 and 18 August; in 2011, on 5 and 21 July, 2 and 23 August, and 2 September. In the non-irrigated side of PRD, the relatively long period of progressive drying determined strong SWP fluctuations reaching at the end of each dry cycle minimum values comprised between -160 and -200 $\mathrm{kPa}$ (Fig. 2). Irrigation by the micro-sprinkler system and volumes applied in each event allowed for a good separation of wet and dry sides of the rootzone in PRD.

Daily changes of tree water status and stomatal conductance

When $\mathrm{WP}_{\text {stem }}$ data of summer 2011 where plotted against the RWC data a significant linear and positive relationship was obtained (Fig. 3). The regression equation was used to convert RWC into $\mathrm{WP}_{\text {stem }}$ which was used to test for relationships with SWP (Fig. 7).

Daily trends of VPD for 9 August 2007 exhibited a first peak around 11:00HR and a second peak right before 18:00HR (Fig. 4A), suggesting partly cloudy conditions in the central part of the day. Radiation data indeed confirmed scattered clouds from 14:00 to 17:30HR (data not shown). Daily $E$ generally showed the typical bell-shaped trend with peaks during the warm hours. In general, PRD and DI leaves transpired less than CI leaves, especially at 11:00 and 15:00HR (Fig. 4B). Generally, $g_{s}$ trends were similar to $E$ trends, although the shape of a bell was less evident for $g_{s}$ of PRD and DI leaves (Fig. 4C). Also in this case, differences in favor of CI leaves were generally observed, and particularly at 11:00 and 15:00HR. As expected, minimum levels of RWC were observed during the warm hours of the day (Fig. 4D). In this case, DI exhibited the lowest RWC and a generally decreasing trend during the day with no apparent ability to recover in the evening hours. On the contrary, RWC of PRD was significantly different (intermediate) from that of CI and DI leaves. In particular, PRD leaves were able to maintain high RWC in the early morning and recover to CI levels in the evening (Fig. 4D).

Seasonal changes of tree water status and stomatal conductance

In 2007, RWC was measured only on 17 July and 31 August and, although DI leaves tended to be somewhat more dehydrated than CI and PRD leaves in both occasions (Tab. 3), the irrigation effect was not significant $(\mathrm{P}=0.325)$. Regardless of irrigation, RWC decreased significantly from mid-July to the end of August $(\mathrm{P}<0.001)$.

In all remaining years (2008-2011), RWC of the three irrigation treatments followed different seasonal trends (significant interaction between irrigation and sampling date). Specifically in 2008, RWC was lower in DI than in CI on 29 July, 12 August and 12 September, whereas RWC was lower in PRD than in CI only on 29 July (Fig. 5A). In 2009, RWC was generally stable throughout the season with PRD lower than CI in two occasions (mid-August and early September) and DI lower than CI in 
one occasion (late August); RWC increased significantly on 14 October in CI and PRD, whereas remained significantly lower in DI (Fig. 5B). In 2010, RWC was lower in DI than in CI throughout July and August and recovered to CI levels in September, whereas RWC was lower in PRD than in CI only on 5 July and 24 August (Fig. 5C). In 2011, RWC was lower in DI than in CI at the end of July and throughout August, and recovered to CI levels in September, whereas RWC was lower in PRD than in CI only on 18 July and 31 August (Fig. 5D). It is interesting to note that RWC was significantly higher in PRD than in DI (true placement effect) only in three occasions, on 12 September 2008, 14 October 2009, and 31 August 2011.

Reductions of $g_{s}$ in deficit irrigation treatments were relatively minor and more consistent in 2007, 2009 and 2011 than in 2008 and 2010, where differences among treatments were rarely significant (Fig. 6). In 2007, $g_{s}$ of DI trees was lowest, and $g_{s}$ of PRD intermediate, on 21 August, 4, 11 and 18 September; on 17 July $g_{s}$ was higher in PRD than in DI trees (Fig. 6A). In 2009, $g_{s}$ of CI trees was significantly higher than $g_{s}$ of PRD and DI on 29 July and 12 August (Fig. 6C). In 2010, $g_{s}$ of DI trees was lowest, and $g_{s}$ of PRD intermediate, only on 10 August (Fig. 6D). In 2011, lower $g_{s}$ in DI than in CI was observed on 16 and 31 August (Fig. 6E). No difference in $g_{s}$ was observed on dates away from the irrigation periods (i.e. late fall, winter, or early spring).

Analysis of soil and plant measurement integrals over the entire seasons showed that the highest SWD int occurred in 2011, followed closely by 2009, and the lowest SWD int occurred in 2007 (Tab. 4). Also, the highest LWSD int occurred in 2009 and the lowest in 2011 and 2007. The highest Gs int occurred in 2010, while the lowest in 2007, 2009 and 2011. Integrals of SWD and LWSD were different in the three irrigation treatments with PRD having intermediate levels between CI and DI (Tab. 4). Specifically, PRD irrigation generated 30\% less $\mathrm{SWD}_{\text {int }}$ and $12 \%$ less $\mathrm{LWSD}_{\text {int }}$ than DI. On the other hand, Gsint was similarly reduced in PRD and DI compared to CI.

When data (average for each sampling date) of all irrigation treatments for the five years of trial were considered together, $\mathrm{WP}_{\text {stem }}$ and $g_{s}$ exhibited a direct and linear relationship with SWP (Fig. 7A and C). Also, $\mathrm{WP}_{\text {stem }}$ and $g_{s}$ were directly related (Fig. 7B) while $g_{s}$ showed a non-linear inverse relationship with VPD (Fig. 7D). On the other hand, when data (average for each sampling date) of the five years of trial were kept separate for the three irrigation treatments, positive correlations of $\mathrm{WP}_{\text {stem }}$ $(\mathrm{r}=0.690, \mathrm{P}<0.001)$ and $g_{s}(\mathrm{r}=0.476, \mathrm{P}=0.025)$ with SWP were found only in PRD (data not shown).

Fruit and shoot growth

Changes in fruit size followed a single-mode trend in 2007 and 2011 and a multi-mode curve in 2008 and 2009 (Fig. 8). In 2008, fruit growth showed a lag period in mid-August (Fig. 8B), while in 2009, fruit showed a rapid size increase in early September to stop growing in October (Fig. 8C).

Fruit diameter was significantly and consistently affected by irrigation only in 2008 (Fig. 8B), although a tendency to gradually show differences with time was also present in the other three years (Fig. $8 \mathrm{~A}, \mathrm{C}$, and D). In particular in 2007, fruit of DI trees were significantly smaller than those of CI trees only by the end of October (Fig. 8A). In 2008, fruit of DI trees were smaller than those of CI and PRD trees starting in mid-July, while fruit of PRD trees never differed from those of CI trees (Fig. 8B). In 2011, fruit of PRD trees were significantly smaller than those of CI trees during September and October (Fig. 8D). In terms of overall seasonal growth, fruit RGR was higher in 2008 than in the other three years and lower in DI than in CI trees (Tab. 5).

In terms of seasonal shoot growth, RGR shoot was highest in 2007 and lowest in 2011 (Tab. 5). The summer flush of growth occurred from mid to the end of July in all years with a second peak at the beginning of September only in 2009 (data not shown). Irrigation did not significantly affect shoot growth (Tab. 5). Also, trunk growth over the five years was similar $(\mathrm{P}=0.938)$ in CI, $\mathrm{PRD}$ and DI trees (0.061, 0.062 and $0.061 \mathrm{~cm}^{2} \mathrm{~cm}^{-2}$ year ${ }^{-1}$, respectively). 
Daily tree water consumption estimated by $E_{\text {tree }}$ was 24 to 36\% higher in 2007 and 2010 compared to 2008, 2009 and 2011 (Tab. 5). Also for this reason, the highest fruit and shoot growth efficiency occurred in 2008. As expected, CI trees consumed significantly more (19\%) water by transpiration than PRD and DI trees. Due to these differences, GRE fruit was similar in all treatments, while $\mathrm{GRE}_{\text {shoot }}$ was higher in PRD trees than in CI trees.

Multiple regression analysis of measurement integrals indicated that, regardless of irrigation treatment, seasonal shoot growth (i.e. total length increment over each irrigation season) can be predicted by a linear combination of $\mathrm{SWD}_{\text {int }}, \mathrm{Gs}_{\mathrm{int}}, \mathrm{VPD}_{\text {int }}$ and $\mathrm{LWSD}_{\text {int }}$ according to the following model: $\mathrm{GR}_{\text {shoot }}=-28.7-0.27 \mathrm{SWD}_{\text {int }}+0.70 \mathrm{Gs}_{\text {int }}+1.01 \mathrm{VPD}_{\text {int }}+0.61 \mathrm{LWSD}_{\text {int }}\left(\mathrm{R}^{2}=0.849, \mathrm{P}<0.001\right)$. Also seasonal fruit growth could be predicted by a linear combination of the same variables according to the following model: $\mathrm{GR}_{\text {fruit }}=45.7-0.48 \mathrm{SWD}_{\text {int }}+2.43 \mathrm{Gs}_{\text {int }}-2.06 \mathrm{VPD}_{\text {int }}+0.53 \mathrm{LWSD}_{\text {int }}\left(\mathrm{R}^{2}=\right.$ $0.962, \mathrm{P}<0.001)$.

When fruit RGR of all five years was pooled together, a general inverse relationship was found with VPD. Yet, the type of relationship was different depending on the irrigation treatment. In CI, fruit RGR decreased rapidly as VPD increased until a threshold of about $2.0 \mathrm{kPa}$ after which it remained constant (Fig. 9A). In PRD, fruit RGR decreased very rapidly until VPD reached about $1.6 \mathrm{kPa}$ after which it continued to decrease at a much slower pace (Fig. 9B). In DI, fruit RGR was generally lower and decreased linearly as VPD increased (Fig. 9C).

\section{Discussion}

The simple reduction of irrigation volumes by $55 \%$ (DI) over conventional irrigation increased by $27 \%$ leaf water deficit and reduced 'Valencia' fruit growth by $15 \%$ but not shoot growth. On the contrary, water savings of about $2,000 \mathrm{~m}^{3} \mathrm{ha}^{-1}$ and per year with PRD did not cause major or significant growth reductions. Differences in fruit growth rates were responsible for reduced yields in DI but not PRD trees, although PRD did not induce any significant advantage in terms of final yield over continuous water deficit. Also, crop loads of 'Valencia' orange trees at harvest were not affected by PRD or DI. This is consistent with previous studies in citrus (Goldhamer and Salinas, 2000; PérezPérez et al., 2012; Kusakabe et al., 2016; Consoli et al., 2017) and suggests that 'Valencia' orange trees tend to retain smaller fruit in response to summer water deficit.

In terms of crop evapotranspiration the five years of investigation were relatively uniform, whereas precipitations were particularly abundant in 2009 and relatively scarce in 2008 (Tab. 1). However, most of the annual rainfall, in 2009 as well as in the other years, was concentrated away from the irrigation period and did not contribute in any particular way to the water balance of the dry season.

Trends of SWP generally reflected changes in soil moisture following the imposition of irrigation treatments and indicated a good separation in time and space of wet and dry zones for the PRD treatment in all five years (Figs. 1 and 2). This is especially important for the efficacy of the PRD technique, and the use of micro-sprinklers, along with duration and interval between irrigation events, proved to be effective. Particular attention should be posed on this aspect, especially in field trials, as PRD functioning is based on the separation and alternation of wet and dry sides of the rootzone, and the lack of these conditions may have been responsible for some negative PRD outcomes. In this regard, continuous recording of SWP proved to be a useful and safe method to monitor time and spatial changes in soil moisture. Differences between SWP of DI rootzones and average SWP of wet and dry PRD rootzones (Fig. 1) are certainly not due to the small difference in irrigation volumes applied to the two treatments (Tab. 2) but rather to a greater wetted soil surface, and consequent soil evaporation, as well as to a shallower watering depth at each irrigation in DI than in PRD (Marsal et al. 2008). When soil water deficit integrals across the irrigation seasons were tested, a clear and significant difference was shown between PRD and DI (DI > PRD), in addition to the expected lower deficit in CI than in PRD and DI (Tab. 4). This is a further evidence of greater evaporation from the soil in DI than in PRD 
due to the deeper and more localized application of water in the latter. The latter generates higher orchard water use efficiency in PRD than in DI (García-Tejera et al., 2017).

Comparative levels of RWC indicate that DI irrigation induced generalized leaf dehydration in all years, whereas PRD generally showed mild leaf dehydration at intermediate levels between CI and DI (Fig. 5). The integration of seasonal trends shows that both deficit treatments induced significant leaf dehydration but indicates also a significantly milder deficit in PRD $(12 \%>\mathrm{CI})$ trees compared to DI $(27 \%>$ CI $)$ trees (Tab. 4). Similar reductions of leaf hydration by PRD were also observed in apple (Einhorn and Caspari 2004; Talluto et al. 2008), lemon (Raveh 2008), orange (Hutton and Loveys 2011; Consoli et al. 2014), grapefruit (Romero-Conde et al. 2014) and Swingle citrumelo seedlings (Melgar et al. 2010).

Reductions of $g_{s}$ in PRD trees were moderate (on average for the five years $12 \%$ less than CI) and only sporadically significant (Fig. 6). DI irrigation generated slightly greater (on average for the five years $16 \%$ less than CI) and, in 2007, more consistent $g_{s}$ reductions than PRD. Nevertheless, Gsint showed similar and significant reductions over CI in both deficit treatments. Similar $g_{s}$ reductions were observed in orange (Hutton and Loveys 2011; Consoli et al. 2014), grapefruit (Romero-Conde et al. 2014), and lemon (Raveh 2008) under PRD. On the contrary, greenhouse-grown citrumelo seedlings did not show significant reductions of $g_{s}$ in response to PRD in spite of increases in leaf ABA (Melgar et al. 2010). The latter was explained by a decrease of stomatal sensitivity to ABA due to severe stress hydraulic signals (Tardieu et al. 1993). This, however, cannot explain the lack of $g_{s}$ reduction in 2007 observed in this study for PRD trees as DI leaves (more dehydrated) did show consistent $g_{s}$ reductions when PRD leaves did not. Overall, this degree of stomatal control in PRD and DI trees was not sufficient to maintain levels of hydration similar to CI trees. Yet, the similar Gsint reduction in PRD and DI (along with greater leaf hydration in PRD than in DI) under greater $\mathrm{SWD}_{\text {int }}$ in DI than in PRD is a clear evidence of an irrigation placement effect (or PRD effect).

It was very hard to find any association between soil, plant and atmosphere variables separately for each irrigation treatment. Yet, when data of all irrigation treatments were pooled together, the direct relationship between soil and leaf water potentials (Fig. 7A) suggests a straight hydraulic signal starting in the soil. Also, a stronger association of $g_{s}$ with $\mathrm{WP}_{\text {stem }}$ than with SWP (Fig. $7 \mathrm{~B}$ and C) suggests a greater stomatal control by a local hydraulic signal than any long distance root-to-shoot signaling. The latter is further supported by the non-linear relationship between $g_{s}$ and VPD (Fig. 7D). Specifically, when a certain VPD threshold is reached, the $g_{s}$ to VPD relationship is inverted, suggesting a hydroactive, negative feedback type of stomatal response (Streck 2003; Steppe et al. 2006), which is possibly due to low leaf turgor (Rodriguez-Dominguez et al., 2016) and/or locally produced ABA. This has been observed also in citrus (Cohen and Cohen 1983; Syvertsen and Lloyd 1994). The latter is indeed known to generate a threshold-type of response (Davies et al. 1994) and justify the non-linear response observed in this study. When data of the three irrigation treatments were kept separate, only PRD trees exhibited a significant correlation between SWP and $g_{s}$ providing some evidence of a root-mediated signal on $g_{s}$ (ABA translocation from root to shoot), and this would be consistent with the PRD mechanism.

No shoot or trunk growth reductions were observed in response to deficit irrigation in this study (Tab. 5). Similarly, PRD did not reduce total plant growth in Swingle citrumelo seedlings (Melgar et al. 2010) or canopy volume and shoot length in field-grown grapefruit (Kusakabe et al. 2016). In contrast, PRD reduced mandarin trunk growth (Kirda et al. 2007) and leaf area of non-bearing, greenhousegrown grapefruit (Romero-Conde et al. 2014). Contrasting results are also reported in other woody crops, and studies on field-grown apples suggest that the vegetative growth response to PRD may depend on seasonal irrigation volumes as well as other growing conditions (O'Connell and Goodwin 2007; Talluto et al. 2008).

Given the similar reductions of $g_{s}$ and $E_{\text {tree }}$ in PRD and DI and the lack of any irrigation effect on vegetative growth, the milder leaf dehydration of PRD compared to DI can be mostly explained by a 
less severe soil water deficit (i.e. DI > PRD). In addition, changes in root functionality and sap flow following partial drying of the rootzone, and specifically increased root sap flows after re-wetting of the dry portion, have been observed in apple (Green and Clothier 1999). To a lesser extent than soil water deficit, increases of root hydraulic conductivity and sap flow may also help explain the greater leaf hydration in PRD than in DI, even in those cases when $g_{s}$ of PRD trees was not reduced.

Seasonal fruit size trends indicated sporadic and inconsistent effects of deficit irrigation and in particular some growth reduction caused by DI (Fig. 8). Indeed, there is evidence in this study that fruit growth rates (Tab. 5) and final yields are reduced only by DI, not PRD. In addition, the absence of a significant interaction between irrigation and year indicates that there was no carry-over effect of the irrigation treatments (i.e. no depletion of stored carbon resources). The lack of a significant fruit growth reduction in PRD trees is consistent with the general concept that PRD irrigation does not affect fruit growth and final yield in citrus (Goldhamer and Salinas 2000; Pérez-Pérez et al. 2012; Kusakabe et al. 2016; Consoli et al. 2017) as well as in other fruit crops (pear, Kang et al. 2002; grape, Gu et al. 2004; mango, Pavel and de Villiers 2004; apple, Francaviglia et al. 2013). It is worth to notice, however, that PRD did not show a consistent advantage over DI, at least in terms of fruit growth or yield and under the conditions of this study.

When growth efficiency was calculated as growth per unit daily tree water consumption, fruit growth efficiency was similar in all irrigation treatments, while shoot growth efficiency was increased by PRD. These results, along with the results on growth rates, indicate that the increase in growth efficiency observed in PRD trees is mostly due to a decrease of water consumption. Yet, the increase of efficiency was preferentially assigned to shoots rather than to fruits. At first sight, this seems rather unusual considering that fruits are generally stronger sinks than shoots and should attract more assimilates for growth even under limiting resources (Pavel and DeJong 1993; Lo Bianco 2009). Yet, multiple regression models as well as simple non-linear associations between VPD and fruit RGR indicated that fruit growth is inversely related to VPD (Fig. 9), while shoot growth can be predicted also by a positive linear relationship with VPD. This concurrent opposite effect of VPD on fruit and shoot growth (along with a generally positive relationship between growth and Gsint) suggests that in PRD under high VPD conditions, water and assimilates are preferentially used for leaf transpiration and shoot growth rather than fruit growth favoring PRD shoot growth efficiency. Indeed, leaves can be strong sinks for xylem water, but also phloem sap (water and nutrients) under high VPD conditions and it has been demonstrated that transpiring citrus leaves retrieve water from fruit (Rokach 1953). This is consistent with observations from other fruit crops where most of the xylem water flows to transpiring leaves during the mid-part of the day (high VPD), while fruit water uptake and RGR are relatively low or negative (backflow) (Lang 1990; Morandi et al. 2007; Morandi et al. 2010; Morandi et al. 2014).

Overall, the results of the present study show good evidence of an irrigation placement effect in addition to the irrigation volume effect. The advantage of a PRD strategy in 'Valencia' orange is evident in both terms of milder soil and leaf water deficit compared to a simple reduction of irrigation volumes. Under PRD, fruits can benefit from sustainable growth rates (similar to conventional irrigation), whereas fruit growth is reduced by long-term water deficit. Despite a fruit growth performance similar to conventionally irrigated trees, PRD did not show any clear advantage over DI in terms of final yield.

\section{Acknowledgments}

We would like to express our sincere thanks to the Sicilian agro-meteorological service (Servizio Informativo Agrometeorologico Siciliano) for providing weather data of the five years of trial used to validate data taken with in-farm meteorological station.

\section{References}


Allen RG, Pereira LS, Raes D, Smith M (1998) Crop evapotranspiration - guidelines for computing crop water requirements. FAO Irrigation and Drainage Paper 56.

Antolín MC, Ayari M, Sánchez-Díaz M (2006) Effects of partial rootzone drying on yield, ripening and berry ABA in potted Tempranillo grapevines with split roots. Austr J Grape Wine Res 12:13-20. doi:10.1111/j.1755-0238.2006.tb00039.x

Ballester C, Castel J, El-Mageed TA, Castel JR, Intrigliolo DS (2014) Long-term response of 'Clementina de Nules' citrus trees to summer regulated deficit irrigation. Agric Water Manag 138:78-84. doi:10.1016/j.agwat.2014.03.003

Caspari HW, Behboudian MH, Chalmers DJ (1994) Water use, growth, and fruit yield of 'Hosui' Asian pears under deficit irrigation. J Amer Soc Hort Sci 119:383-388

Chalmers DJ, Mitchell PD, van Heek LAG (1981) Control of peach tree growth and productivity by regulated water supply, tree density, and summer pruning. J Amer Soc Hort Sci 106:307-312.

Cohen S, Cohen Y (1983) Field studies of leaf conductance response to environmental variables in citrus. J Appl Ecol 20:561-570. doi:10.2307/2403526

Consoli S, Stagno F, Roccuzzo G, Cirelli GL, Intrigliolo F (2014) Sustainable management of limited water resources in a young orange orchard. Agric Water Manag 132:60-68. doi:10.1016/j.agwat.2013.10.006

Consoli S, Stagno F, Vanella D, Boaga J, Cassiani G, Roccuzzo G (2017) Partial root-zone drying irrigation in orange orchards: Effects on water use and crop production characteristics. Eur J Agron 82:190-202. doi:10.1016/j.eja.2016.11.001

Davies WJ, Tardieu F, Trejo CL (1994) How do chemical signals work in plants that grow in drying soil? Plant Physiol 104:309-314. doi:10.1104/pp.104.2.309

Davies WJ, Wilinson S, Loveys B (2002) Stomatal control by chemical signalling and the exploitation of this mechanism to increase water use efficiency in agriculture. New Phytol 153:449-460

Dry PR, Loveys BR (1998) Factors influencing grapevine vigour and the potential for control with partial rootzone drying. Austr J Grape Wine Res 4:140-148. doi:10.1111/j.17550238.1998.tb00143.x

Dry PR, Loveys BR (1999) Grapevine shoot growth and stomatal conductance are reduced when part of the root system is dried. Vitis 38: 151-156.

Dry PR, Loveys BR, Botting DG, Düring H (1995) Effects of partial rootzone drying on grapevine vigour, yield, composition of fruit and use of water. Proc Ninth Aust Wine Ind Tech Conf 128-131.

Dry PR, Loveys BR, Düring H (2000) Partial drying of the rootzone of grape. I. Transient changes in shoot growth and gas exchange. Vitis 39:3-7.

Einhorn T, Caspari HW (2004) Partial root-zone drying and deficit irrigation of 'Gala' apples in a semiarid climate. Acta Hort 664:197-204. doi:10.17660/actahortic.2004.664.22

Eliades G, Georgiou A, Papadopoulos I (2004) Effect of conventional irrigation and alternate rootzone drying with sufficient or deficient irrigation water on the production of marsh seedless grapefruit. Agric Mediterranea 134:78-184.

Faber BA, and Lovatt CJ (2014) Effects of applying less water by partial root zone drying versus conventional irrigation on navel orange yield. Acta Hort 1038:523-530. doi:10.17660/ActaHortic.2014.1038.65

Francaviglia D, Farina V, Avellone G, Lo Bianco R (2013) Fruit yield and quality responses of apple cvars Gala and Fuji to partial rootzone drying under Mediterranean conditions. J Agric Sci 151:556569. doi:10.1017/S0021859612000718

García-Tejera O, López-Bernal Á, Orgaz F, Testi L, Villalobos FJ (2017) Analysing the combined effect of wetted area and irrigation volume on olive tree transpiration using a SPAC model with a multicompartment soil solution. Irrig Sci 35:409-423 
García-Tejero I, Romero-Vicente R, Jiménez-Bocanegra JA, Martínez-García G, Durán-Zuazo VH, Muriel-Fernández JL (2010) Response of citrus trees to deficit irrigation during different phenological periods in relation to yield, fruit quality, and water productivity. Agric Water Manag 97:689-699. doi:10.1016/j.agwat.2009.12.012

García-Tejero I, Durán-Zuazo VH, Jiménez-Bocanegra JA, Muriel-Fernández JL (2011) Improved water-use efficiency by deficit-irrigation programmes: Implications for saving water in citrus orchards. Sci Hort 128:274-282. doi:10.1016/j.scienta.2011.01.035

Gasque M, Martí P, Granero B, González-Altozano P (2016) Effects of long-term summer deficit irrigation on 'Navelina' citrus trees. Agric Water Manag 169:140-147.

Goldhamer DA, Beede RH (2004). Regulated deficit irrigation effects on yield, nut quality and wateruse efficiency of mature pistachio trees. J Hort Sci Biotech 79:538-545. doi:10.1080/14620316.2004.11511802

Goldhamer DA, Salinas M (2000) Evaluation of regulated deficit irrigation on mature orange trees grown under high evaporative demand. In: Proc. Intl. Soc. Citricult. IX Congr (Vol. 1, pp. 227-231).

Goldhamer DA, Viveros M, Salinas M (2006) Regulated deficit irrigation in almonds: effects of variations in applied water and stress timing on yield and yield components. Irrig Sci 24:101-114. doi:10.1007/s00271-005-0014-8

González-Altozano P, Castel JL (1999). Regulated deficit irrigation in 'Clementina de Nules' citrus trees. I. Yield and fruit quality effects. J Hort Sci Biotech 74:706-713. doi:10.17660/actahortic.2000.537.89

Gowing DJG, Davies WJ, Jones HG (1990) A positive root-sourced signal as an indicator of soil drying in apple, Malus $\times$ domestica Borkh. J Exp Bot 41:1535-1540. doi:10.1093/jxb/41.12.1535

Green SR, Clothier B (1999) The root zone dynamics of water uptake by a mature apple tree. Plant Soil 206:61-77. doi:10.1023/A:1004368906698

Gu S, Du G, Zoldoske D, Hakim A, Cochran R, Fugelsang K, Jorgensen G (2004) Effects of irrigation amount on water relations, vegetative growth, yield and fruit composition of Sauvignon blanc grapevines under partial rootzone drying and conventional irrigation in the San Joaquin Valley of California, USA. J Hort Sci Biotech 79:26-33. doi:10.1080/14620316.2004.11511732

Hutton RJ, Loveys BR (2011) A partial root zone drying irrigation strategy for citrus - Effects on water use efficiency and fruit characteristics. Agric Water Manag 98:1485-1496. doi:10.1016/j.agwat.2011.04.010

Kang S, Hu X, Goodwin I, Jerie P (2002) Soil water distribution, water use, and yield response to partial root zone drying under a shallow groundwater table condition in a pear orchard. Sci Hort 92:277-291. doi:10.1016/s0304-4238(01)00300-4

Kirda C, Topaloğlu F, Topçu S, Kaman H (2007) Mandarin yield response to partial root drying and conventional deficit irrigation. Turkish J Agric Forestry 31:1-10.

Kusakabe A, Contreras-Barragan BA, Simpson CR, Enciso JM, Nelson SD, Melgar JC (2016) Application of partial rootzone drying to improve irrigation water use efficiency in grapefruit trees. Agric Water Manag 178:66-75. doi:10.1016/j.agwat.2016.09.012

Lampinen BD, Shackel KA, Southwick SM, Olson B, Yeager JT, Goldhamer D (1995) Sensitivity of yield and fruit quality of French prune to water deprivation at different fruit growth stages. J Amer Soc Hort Sci 120:139-147.

Leib BG, Caspari HW, Redulla CA, Andrews PK, Jabro JJ (2006) Partial rootzone drying and deficit irrigation of 'Fuji' apples in semi-arid climate. Irrig Sci 24:85-99. doi:10.1007/s00271-005-0013-9

Lo Bianco R (2009) Carbohydrate metabolism and source-sink relationships in peach. In: Karam WP (ed) Tree Growth: Influences, Layers and Types, Nova Science Publishers, New York, pp 79-91.

Lo Bianco R, Francaviglia D (2012) Comparative responses of 'Gala' and 'Fuji' apple trees to deficit irrigation: placement versus volume effects. Plant Soil 357:41-58. doi:10.1007/s11104-012-1149-Z 
Marino G, Pernice F, Marra FP, Caruso T (2016) Validation of an online system for the continuous monitoring of tree water status for sustainable irrigation managements in olive (Olea europaea L.). Agric Water Manag 177:298-307. doi:10.1016/j.agwat.2016.08.010

Marra FP, Marino G, Marchese A, Caruso T (2016) Effects of different irrigation regimes on a superhigh-density olive grove cv. 'Arbequina': vegetative growth, productivity and polyphenol content of the oil. Irrig Sci 34:313-325. doi:10.1007/s00271-016-0505-9

Marsal J, Mata M, Del Campo J, Arbones A, Vallverdú X, Girona J, Olivo N (2008) Evaluation of partial root-zone drying for potential field use as a deficit irrigation technique in commercial vineyards according to two different pipeline layouts. Irrig Sci 26:347-356. doi:10.1007/s00271007-0098-4

Melgar JC, Dunlop JM, Syvertsen JP (2010) Growth and physiological responses of the citrus rootstock Swingle citrumelo seedlings to partial rootzone drying and deficit irrigation. J Agric Sci 148-593602. doi:10.1017/s0021859610000377

Mitchell PD, Chalmers DJ (1982) The effect of reduced water supply on peach tree growth and yields. J Amer Soc Hort Sci 107:853-56

Morandi B, Rieger M, Corelli Grappadelli L (2007) Vascular flows and transpiration affect peach (Prunus persica Batsch.) fruit daily growth. J Exp Bot 58:3941-47. doi:10.1093/jxb/erm248

Morandi B, Manfrini L, Losciale P, Zibordi M, Corelli Grappadelli L (2010) Changes in vascular and transpiration flows affect the seasonal and daily growth of kiwifruit (Actinidia deliciosa) berry. Ann Bot 105:913-23. doi:10.1093/aob/mcq070

Morandi B, Losciale P, Manfrini L, Zibordi M, Anconelli S, Pierpaoli E, Corelli Grappadelli L (2014) Leaf gas exchanges and water relations affect the daily patterns of fruit growth and vascular flows in Abbé fétel pear (Pyrus communis L.) trees. Sci Hort 178:106-13. doi:10.1016/j.scienta.2014.08.009

Moriana A, Orgaz F, Pastor M, Fereres E (2003) Yield responses of mature olive orchard to water deficits. J Amer Soc Hort Sci 123:425-431.

Myers BJ (1988) Water stress integral. A link between short term stress and long term growth. Tree Physiol 4:315-323. doi:10.1093/treephys/4.4.315

O'Connell MG, Goodwin I (2007) Responses of 'Pink Lady' apple to deficit irrigation and partial rootzone drying: physiology, growth, yield and fruit quality. Austr J Agric Res 58:1068-1076. doi:10.1071/ar07033

Pavel E, DeJong T (1993) Source-and sink-limited growth periods of developing peach fruits indicated by relative growth rate analysis. J Amer Soc Hort Sci 118:820-24.

Pavel EW, de Villiers AJ (2004) Responses of mango trees to reduced irrigation regimes. Acta Hort 646:63-68. doi:10.17660/actahortic.2004.646.7

Pérez-Pérez JG, Dodd IC, Botía P (2012) Partial rootzone drying increases water-use efficiency of lemon Fino 49 trees independently of root-to-shoot ABA signalling. Funct Plant Biol 39:366 -78. doi:10.1071/FP11269

Pérez-Pérez JG, Romero P, Navarro JM, Botía P (2008) Response of sweet orange cv 'Lane late' to deficit-irrigation strategy in two rootstocks. II: Flowering, fruit growth, yield and fruit quality. Irrig Sci 26:519-529. doi:10.1007/s00271-008-0113-4

Raveh E (2008) Partial root-zone drying as a possible replacement for 'Verdelli' practice in lemon production. Acta Hort 792:537-541. doi:10.17660/actahortic.2008.792.62

Rodriguez - Dominguez CM, Buckley TN, Egea G, Cires A, Hernandez - Santana V, Martorell S, Diaz - Espejo A (2016) Most stomatal closure in woody species under moderate drought can be explained by stomatal responses to leaf turgor. Plant Cell Envir 39:2014-2026. doi:10.1111/pce. 12774

Rokach A (1953) Water transfer from fruits to leaves in the Shamouti orange tree and related topics. Palestine J Bot 8:146-51. 
Romero-Conde A, Kusakabe A, Melgar JC (2014) Physiological responses of citrus to partial rootzone drying irrigation. Sci Hort 169:234-238. doi:10.1016/j.scienta.2014.02.022

Ruiz-Sànchez MC, Torrecillas A, Perez-Pastor A, Domingo R (2000) Regulated deficit irrigation in apricot trees. Acta Hort 537, 759-766. doi:10.17660/actahortic.2000.537.90

Sadras VO (2009) Does partial root-zone drying improve irrigation water productivity in the field? A meta-analysis. Irrig Sci 27:183-190. doi:10.1007/s00271-008-0141-0

Spreer W, Nagle M, Neidhart S, Carle R, Ongprasert S, Müller J (2007) Effect of regulated deficit irrigation and partial rootzone drying on the quality of mango fruits (Mangifera indica L., cv. 'Chok Anan'). Agric Water Manag 88:173-180. doi:10.1016/j.agwat.2006.10.012

Steppe K, Dzikiti S, Lemeur R, Milford JR (2006) Stomatal oscillations in orange trees under natural climatic conditions. Ann Bot 97: 831-835. doi:10.1093/aob/mcl031

Stoll M, Loveys B, Dry P (2000) Hormonal changes induced by partial rootzone drying of irrigated grapevine. J Exp Bot 51:1627-1634. doi:10.1093/jexbot/51.350.1627

Streck NA (2003) Stomatal response to water vapor pressure deficit: an unsolved issue. Rev Bras Agrociência 9:317-322.

Syvertsen JP (1985) Integration of water stress in fruit trees. HortScience 20:1039-1043.

Syvertsen JP, Lloyd J (1994) Citrus. In: Schaffer B, Andersen PC (eds) Handbook of Environmental Physiology of Fruit Crops: Sub-Tropical and Tropical Crops, CRC Press, Boca Raton, pp 65-99.

Talluto G, Farina V, Volpe G, Lo Bianco R (2008) Effects of partial rootzone drying and rootstock vigour on growth and fruit quality of 'Pink Lady' apple trees in Mediterranean environments. Austr J Agric Res 59:785-94. doi:10.1071/ar07458

Tardieu F, Davies WJ (1993) Integration of hydraulic and chemical signalling in the control of stomatal conductance and water status of droughted plants. Plant Cell Environ 16:341-349. doi:10.1111/j.1365-3040.1993.tb00880.x

Treeby MT, Henriod RE, Bevington KB, Milne DJ, Storey R (2007) Irrigation management and rootstock effects on navel orange [Citrus sinensis (L.) Osbeck] fruit quality. Agric Water Manag 91:24-32. doi:10.1016/j.agwat.2007.04.002

Wahbi S, Wakrim R, Aganchich B, Tahi H, Serraj R (2005) Effects of partial rootzone drying (PRD) on adult olive tree (Olea europaea) in field conditions under arid climate I. Physiological and agronomic responses. Agric Ecosyst Environ 106:289-301. doi:10.1016/j.agee.2004.10.015

Zhang J, Davies WJ (1987) Increased synthesis of ABA in partially dehydrated root tips and ABA transport from roots to leaves. J Exp Bot 38:2015-2023. doi:10.1093/jxb/38.12.2015 
Table 1 Distribution of annual rainfall $(\mathrm{mm})$ and crop evapotranspiration $\left(\mathrm{ET}_{\mathrm{c}}, \mathrm{mm}\right)$ recorded at the experimental site in Palermo (30 $06^{\prime} \mathrm{N}, 13^{\circ} 21^{\prime} \mathrm{E}$, and $31 \mathrm{~m}$ a.s.l.), Sicily, in the five years of trial.

\begin{tabular}{ccccccc}
\hline Year & Water in/out & Spring & Summer & Fall & Winter & Year total \\
\hline $\mathbf{2 0 0 7}$ & Rainfall & 138 & 11 & 364 & 151 & 664 \\
& ETc & 218 & 312 & 93 & 78 & 701 \\
$\mathbf{2 0 0 8}$ & Rainfall & 77 & 24 & 260 & 95 & 456 \\
& ETc & 238 & 303 & 97 & 81 & 720 \\
$\mathbf{2 0 0 9}$ & Rainfall & 137 & 12 & 648 & 441 & 1238 \\
& ETc & 235 & 302 & 93 & 86 & 715 \\
$\mathbf{2 0 1 0}$ & Rainfall & 55 & 10 & 303 & 374 & 742 \\
& ETc & 228 & 313 & 106 & 87 & 733 \\
$\mathbf{2 0 1 1}$ & Rainfall & 65 & 14 & 285 & 266 & 630 \\
& ETc & 229 & 317 & 106 & 81 & 733 \\
\hline
\end{tabular}

Table 2 Irrigation period and total volumes for the five years of trial.

\begin{tabular}{ccccccc}
\hline Year & Start & End & N. events & \multicolumn{3}{c}{ Volumes (mm) } \\
\hline & & & & CI & PRD & DI \\
\hline $\mathbf{2 0 0 7}$ & 29 Jun & 18 Sep & 21 & 345 & 160 & 154 \\
$\mathbf{2 0 0 8}$ & 18 Jun & 11 Sep & 20 & 340 & 140 & 132 \\
$\mathbf{2 0 0 9}$ & 23 Jun & 7 Sep & 21 & 345 & 149 & 140 \\
$\mathbf{2 0 1 0}$ & 18 Jun & 8 Sep & 26 & 425 & 183 & 176 \\
$\mathbf{2 0 1 1}$ & 02 Jun & 12 Sep & 20 & 344 & 169 & 211 \\
\hline
\end{tabular}

Table 3 Leaf relative water content (RWC, \%) in adult 'Valencia' orange trees under conventional irrigation (CI), partial rootzone drying (PRD), and continuous deficit irrigation (DI) in summer 2007. Means \pm standard errors $(\mathrm{n}=16)$.

\begin{tabular}{lcc}
\hline Irrigation & July $\mathbf{1 7}$ & August 31 \\
\hline CI & $88.2 \pm 1.01$ & $85.8 \pm 1.70$ \\
PRD & $87.2 \pm 0.84$ & $84.2 \pm 1.07$ \\
DI & $86.4 \pm 1.15$ & $82.0 \pm 1.45$ \\
\hline \multicolumn{2}{c}{ P values from ANOVA } \\
Irrigation & 0.095 \\
Time & 0.002 \\
Irrig X Time & 0.672 \\
\hline
\end{tabular}




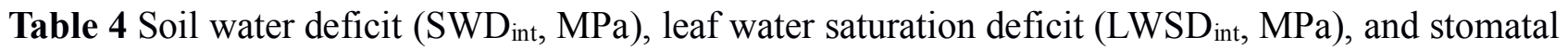

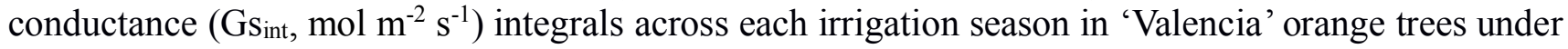
conventional irrigation (CI), partial rootzone drying (PRD), and continuous deficit irrigation (DI) during the five years of trial. Mean separation by Tukey's multiple range test $(\mathrm{P}<0.05)$. Different letters indicate significant differences within each column and factor.

\begin{tabular}{cccc}
\hline & SWD $_{\text {int }}$ & LWSD $_{\text {int }}$ & Gsint $^{\text {Y }}$ \\
\hline \multicolumn{5}{c}{ Year } \\
\hline $\mathbf{2 0 0 7}$ & $3.01 \mathrm{~b}$ & $10.8 \mathrm{~cd}$ & $5.82 \mathrm{c}$ \\
$\mathbf{2 0 0 8}$ & $4.89 \mathrm{ab}$ & $12.2 \mathrm{bc}$ & $7.44 \mathrm{~b}$ \\
$\mathbf{2 0 0 9}$ & $5.23 \mathrm{ab}$ & $15.3 \mathrm{a}$ & $5.49 \mathrm{c}$ \\
$\mathbf{2 0 1 0}$ & $3.85 \mathrm{ab}$ & $12.4 \mathrm{~b}$ & $9.93 \mathrm{a}$ \\
$\mathbf{2 0 1 1}$ & $5.55 \mathrm{a}$ & $9.76 \mathrm{~d}$ & $5.91 \mathrm{c}$ \\
\hline \multicolumn{5}{c}{ Irrigation } \\
CI & $2.02 \mathrm{c}$ & $10.7 \mathrm{c}$ & $7.65 \mathrm{a}$ \\
PRD & $4.76 \mathrm{~b}$ & $12.0 \mathrm{~b}$ & $6.71 \mathrm{~b}$ \\
DI & $6.74 \mathrm{a}$ & $13.6 \mathrm{a}$ & $6.39 \mathrm{~b}$ \\
\hline \multicolumn{5}{c}{ P values from ANOVA } \\
Irrigation & $<0.001$ & $<0.001$ & $<0.001$ \\
Time & 0.023 & $<0.001$ & $<0.001$ \\
Irrig X Time & 0.847 & 0.066 & 0.336 \\
\hline
\end{tabular}

Table 5 Fruit relative growth rate $\left(\mathrm{RGR}_{\text {fruit }}, \mathrm{mm} \mathrm{mm}^{-1}\right.$ day $\left.^{-1} 10^{-2}\right)$, shoot relative elongation rate $\left(\mathrm{RGR}_{\text {shoot}}, \mathrm{mm} \mathrm{mm}^{-1} \mathrm{day}^{-1} 10^{-2}\right)$, daily tree transpiration $\left(E_{\text {tree }}, \mathrm{L}_{\text {day }}{ }^{-1}\right)$, fruit growth rate efficiency $\left(G_{\text {fruit }}, \mathrm{mm} \mathrm{mm}^{-1} \mathrm{~m}^{-3}\right)$ and shoot growth rate efficiency $\left(\mathrm{GRE}_{\text {shoot}}, \mathrm{mm} \mathrm{mm}^{-1} \mathrm{~m}^{-3}\right)$ in 'Valencia' orange trees under conventional irrigation (CI), partial rootzone drying (PRD), and continuous deficit irrigation (DI) during the five years of observations. Mean separation by Tukey's multiple range test (P $<0.05)$. Different letters indicate significant differences within each column and factor.

\begin{tabular}{cccccc}
\hline & RGR $_{\text {fruit }}$ & RGR $_{\text {shoot }}$ & $\boldsymbol{E}_{\text {tree }}$ & $\mathbf{G R E}_{\text {fruit }}$ & GRE $_{\text {shoot }}$ \\
\hline \multicolumn{7}{c}{ Year } \\
\hline $\mathbf{2 0 0 7}$ & $0.633 \mathrm{~b}$ & $0.211 \mathrm{a}$ & $58.3 \mathrm{a}$ & $0.108 \mathrm{~b}$ & $0.039 \mathrm{ab}$ \\
$\mathbf{2 0 0 8}$ & $0.908 \mathrm{a}$ & $0.209 \mathrm{a}$ & $48.2 \mathrm{~b}$ & $0.187 \mathrm{a}$ & $0.050 \mathrm{a}$ \\
$\mathbf{2 0 1 0}$ & $0.513 \mathrm{c}$ & $0.145 \mathrm{ab}$ & $44.3 \mathrm{~b}$ & $0.115 \mathrm{~b}$ & $0.033 \mathrm{ab}$ \\
$\mathbf{2 0 1 1}$ & - & $0.186 \mathrm{ab}$ & $59.1 \mathrm{a}$ & - & $0.038 \mathrm{ab}$ \\
\hline \multicolumn{7}{c}{$0.094 \mathrm{~b}$} & $43.0 \mathrm{~b}$ & $0.109 \mathrm{~b}$ & $0.022 \mathrm{~b}$ \\
\hline CI & $0.486 \mathrm{c}$ & Irrigation \\
PRD & $0.687 \mathrm{a}$ & 0.153 & $56.3 \mathrm{a}$ & 0.127 & $0.027 \mathrm{~b}$ \\
DI & $0.608 \mathrm{ab}$ & 0.187 & $48.3 \mathrm{~b}$ & 0.127 & $0.042 \mathrm{a}$ \\
\hline \multicolumn{7}{c}{0.169} & $46.7 \mathrm{~b}$ & 0.124 & $0.035 \mathrm{ab}$ \\
Irrigation & 0.041 & 0.630 & $<0.001$ & 0.932 & 0.046 \\
Time & $<0.001$ & $<0.001$ & $<0.001$ & $<0.001$ & 0.015 \\
Irrig X Time & 0.859 & 0.072 & 0.202 & 0.466 & 0.419 \\
\hline
\end{tabular}




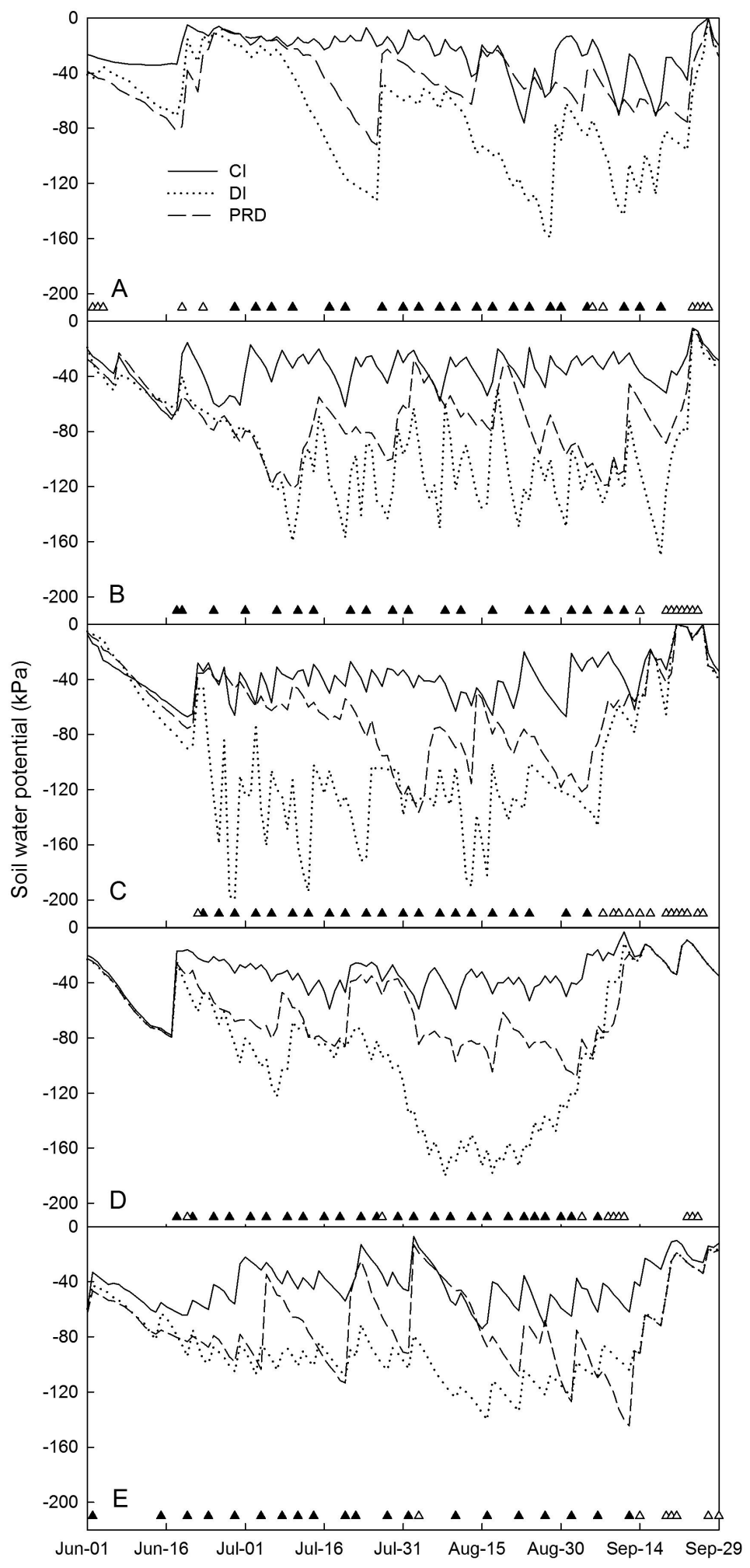

Fig. 1 Soil water potential in the rootzone of 'Valencia' orange trees under conventional irrigation (CI), continuous deficit irrigation (DI), and partial rootzone drying (PRD, average of wet and dry side) during the 2007 (A), 2008 (B), 2009 (C), 2010 (D), and 2011 (E) irrigation seasons. Triangles at the bottom of each panel indicate irrigation (black) or rainfall (white) events. 


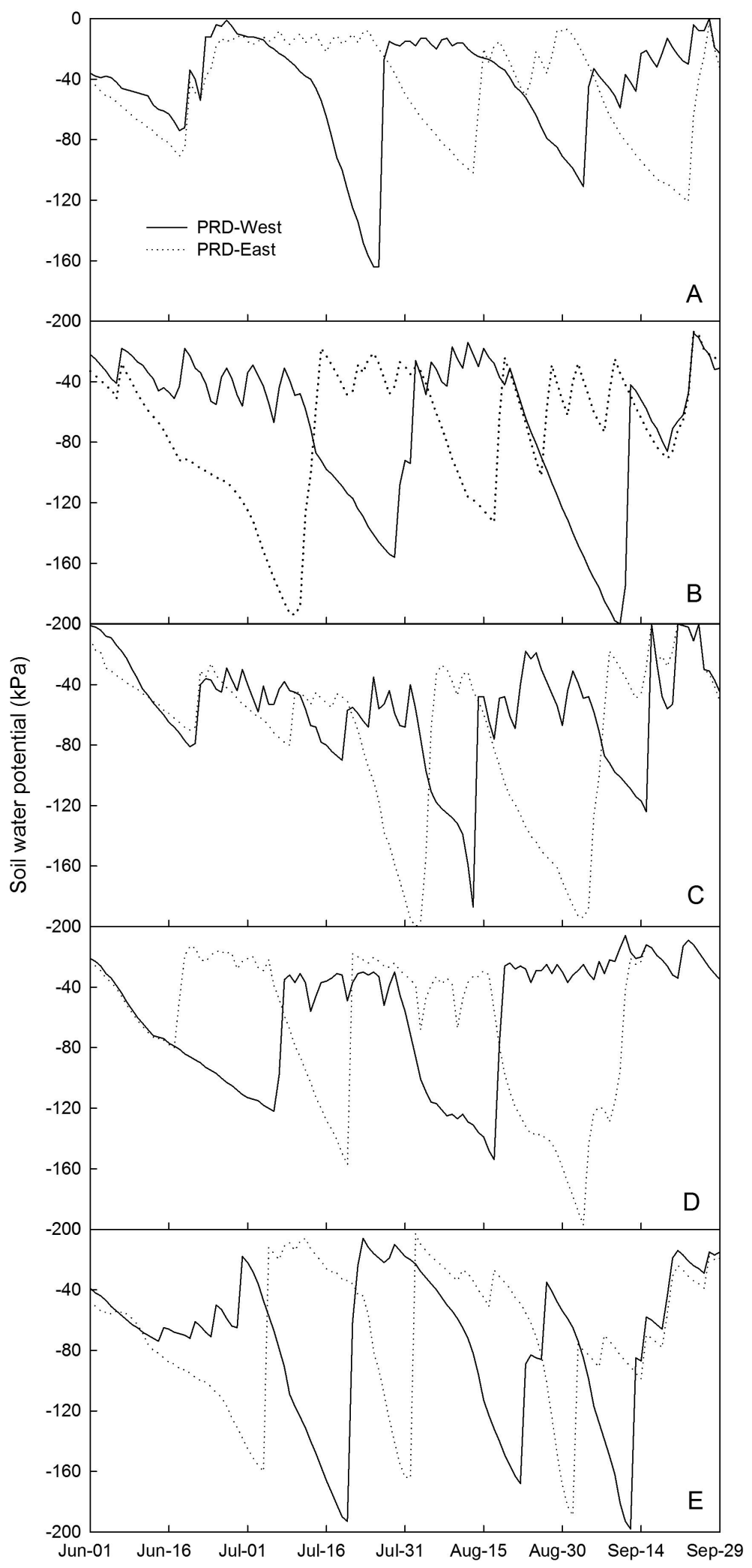

Fig. 2 Soil water potential in the West and East rootzone sides of 'Valencia' orange trees under partial rootzone drying (PRD) during the 2007 (A), 2008 (B), 2009 (C), 2010 (D), and 2011 (E) irrigation seasons. 


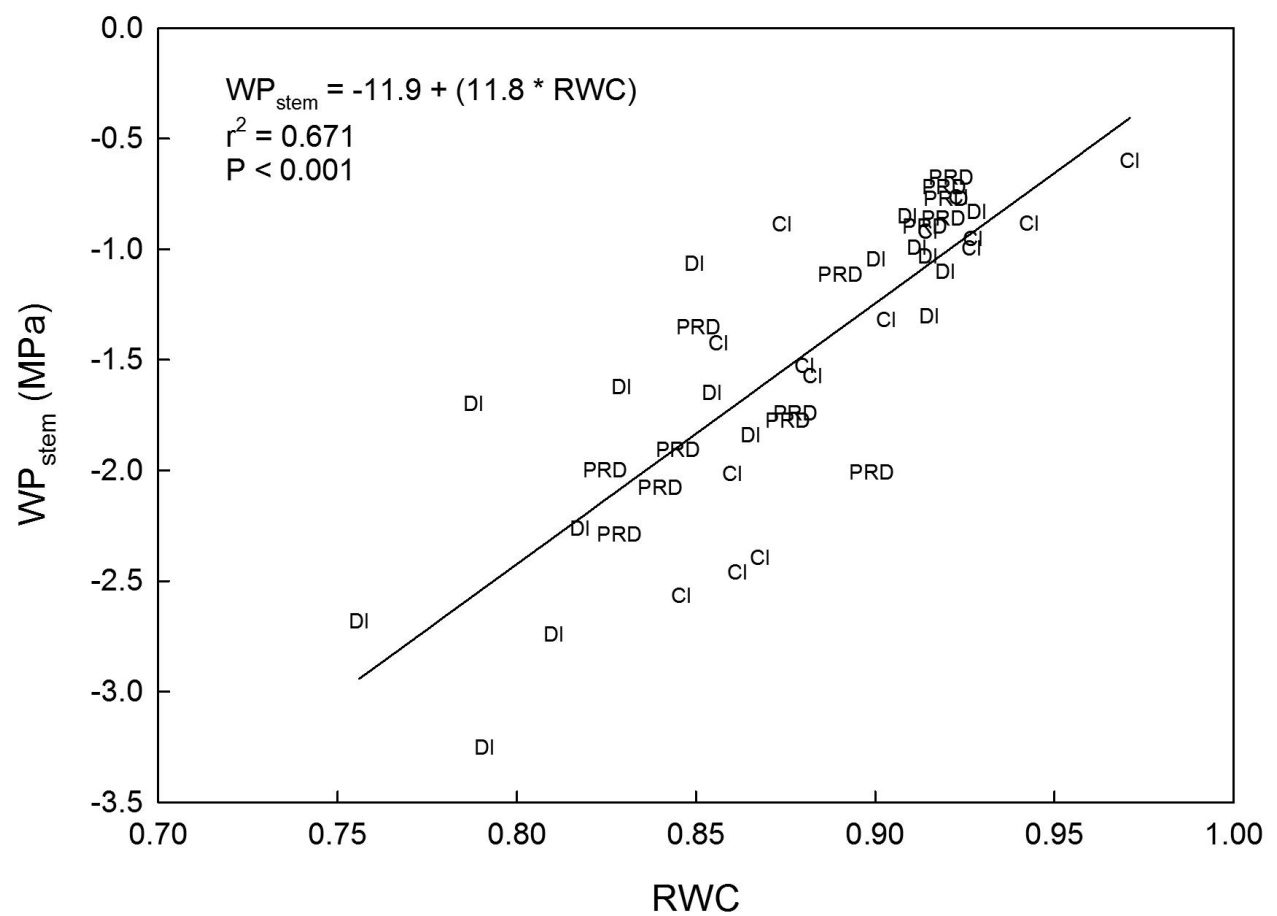

Fig. 3 Relationship between leaf relative water content (RWC) and stem water potential (WPstem) in 'Valencia' orange trees under conventional irrigation (CI), partial rootzone drying (PRD), and continuous deficit irrigation (DI). Data are from summer 2011 and measurements from CI, PRD and DI trees were pooled together. 


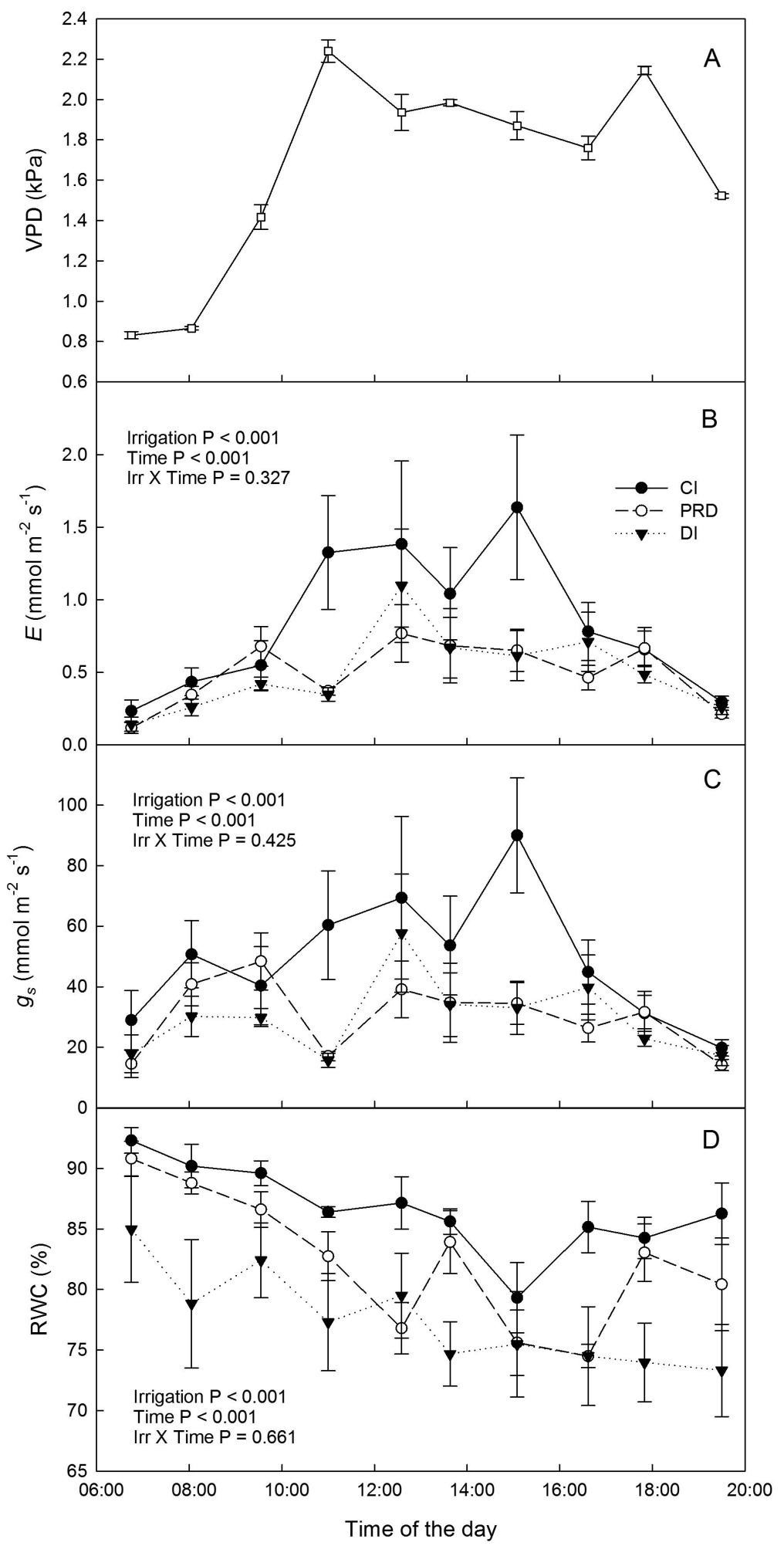

Fig. 4 Daily changes of vapor pressure deficit (VPD, A) and leaf transpiration $(E, \mathrm{~B})$, stomatal conductance $\left(g_{s}, \mathrm{C}\right)$ and relative water content $(\mathrm{RWC}, \mathrm{D})$ in 'Valencia' orange trees under conventional irrigation (CI), partial rootzone drying (PRD), and continuous deficit irrigation (DI) on 9 August 2007. $P$ values in each panel refer to factors from the analysis of variance. Error bars represent standard errors of means $(n=4)$. 


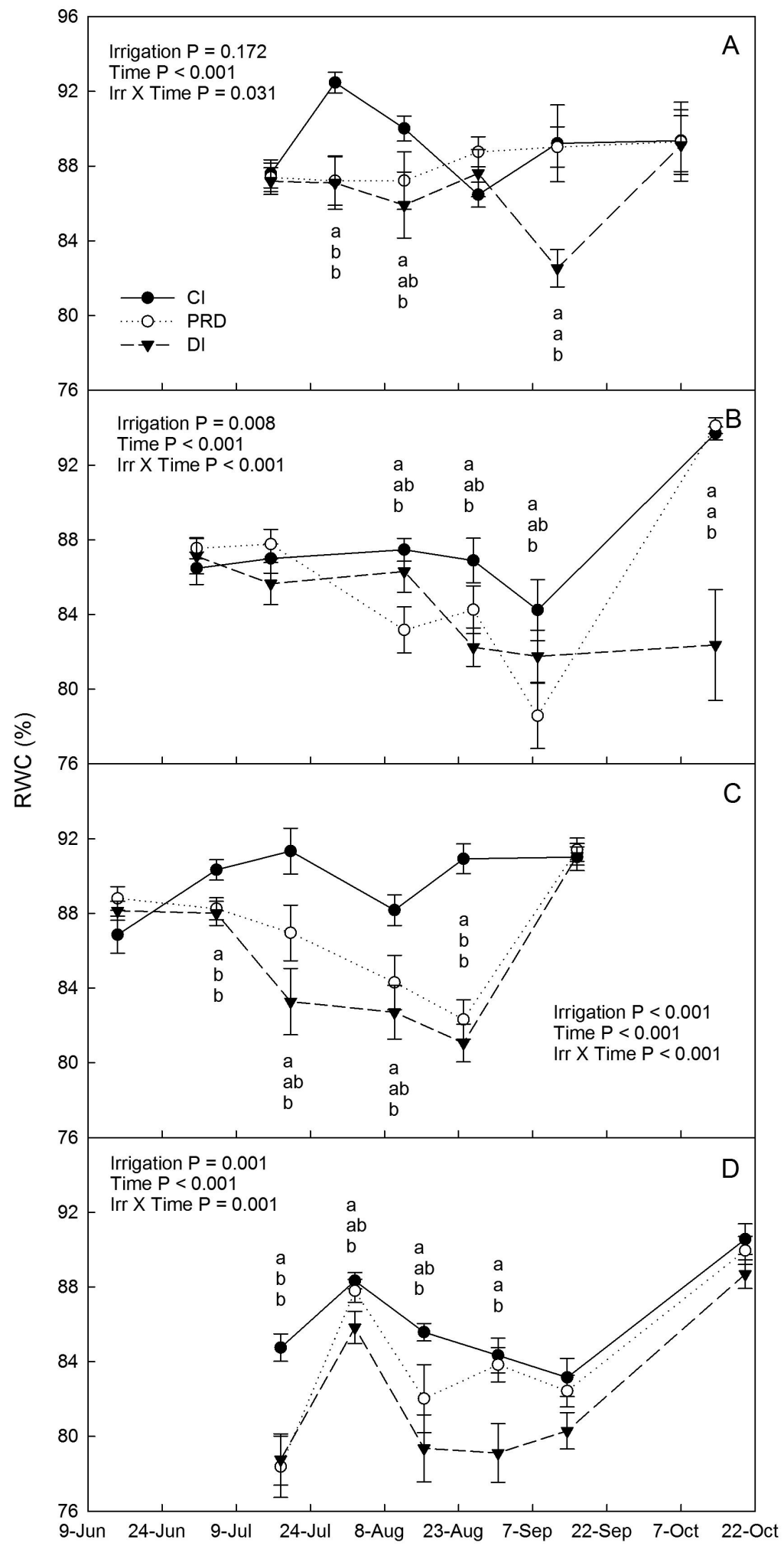

Fig. 5 Leaf relative water content (RWC) in 'Valencia' orange trees under conventional irrigation (CI), partial rootzone drying (PRD), and continuous deficit irrigation (DI) in 2008 (A), 2009 (B), 2010 (C), and 2011 (D). Error bars represent standard errors of the means. When present, different letters indicate significant differences among irrigation treatments for a specific date (Tukey's test, $\mathrm{P}<0.05$ ). 


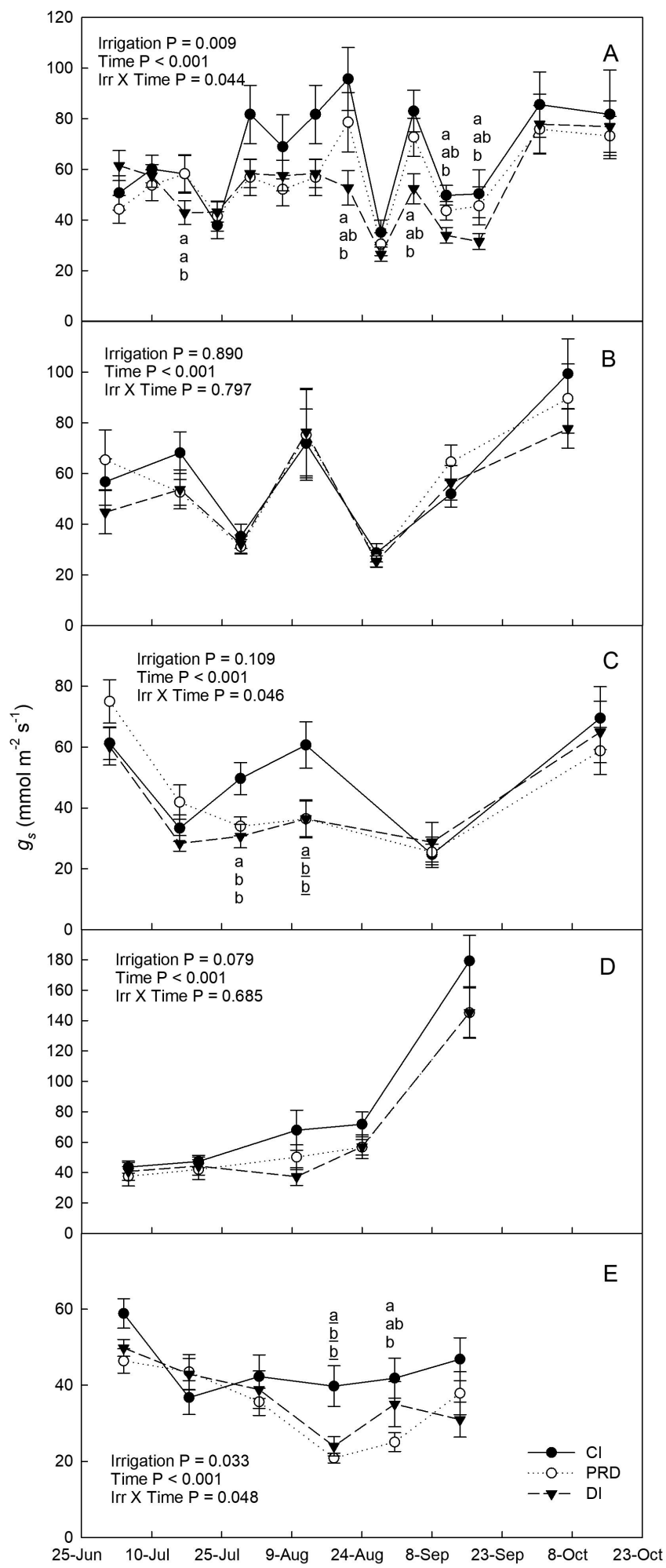

Fig. 6 Leaf stomatal conductance $\left(g_{s}\right)$ in 'Valencia' orange trees under conventional irrigation (CI), partial rootzone drying (PRD), and continuous deficit irrigation (DI) in 2007 (A), 2008 (B), 2009 (C), 2010 (D) and 2011 (E). Different y-scale ranges are used in each panel. Error bars represent standard errors of the means. When present, different letters indicate significant differences among irrigation treatments for a specific date (Tukey's test, $\mathrm{P}<0.05$ ). 

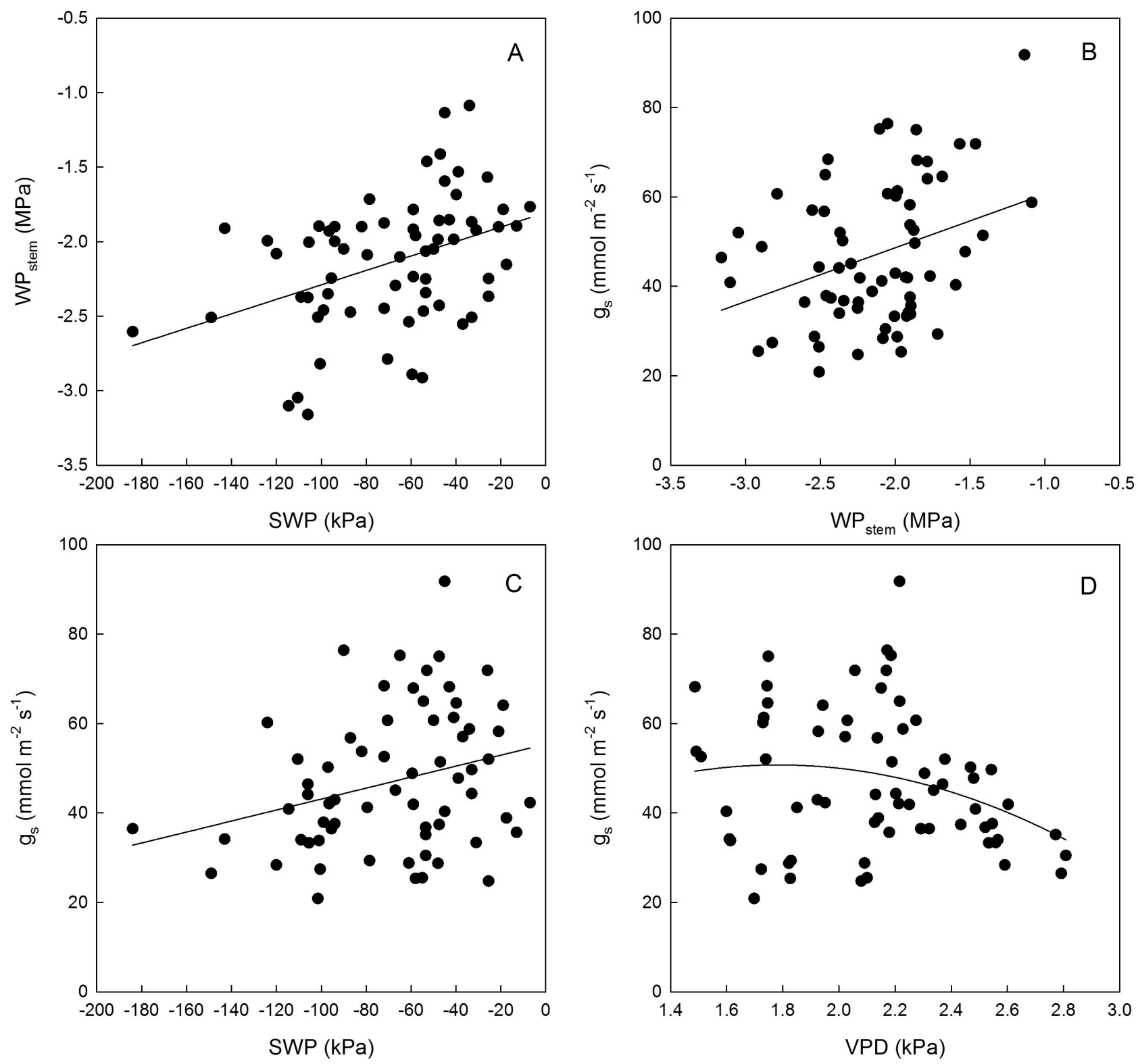

Fig. 7 Relationships between (A) soil water potential (SWP) and stem water potential (WP stem $_{\text {), (B) }}$ $\mathrm{WP}_{\text {stem }}$ and stomatal conductance $\left(g_{s}\right),(\mathrm{C}) \mathrm{SWP}$ and $g_{s},(\mathrm{D})$ vapor pressure deficit (VPD) and $g_{s}$ in leaves of 'Valencia' orange trees under conventional irrigation (CI), partial rootzone drying (PRD), and continuous deficit irrigation (DI). Data points are averages for each sampling date and irrigation treatment during the five years of trial. Data from the three irrigation treatments were pooled in the same regression. In $\mathrm{A}, \mathrm{WP}_{\text {stem }}=-1.80+0.005 \mathrm{SWP}\left(\mathrm{R}^{2}=0.159, \mathrm{P}<0.001\right)$; in $\mathrm{B}, g_{s}=72.7+$ $12.0 \mathrm{WP}_{\text {stem }}\left(\mathrm{R}^{2}=0.113, \mathrm{P}=0.006\right)$; in $\mathrm{C}, g_{s}=55.4+0.123 \mathrm{SWP}\left(\mathrm{R}^{2}=0.080, \mathrm{P}<0.022\right)$; in $\mathrm{D}, g_{s}=$ $56.9 \mathrm{VPD}-15.9 \mathrm{VPD}^{2}\left(\mathrm{R}^{2}=0.091, \mathrm{P}<0.014\right)$. 


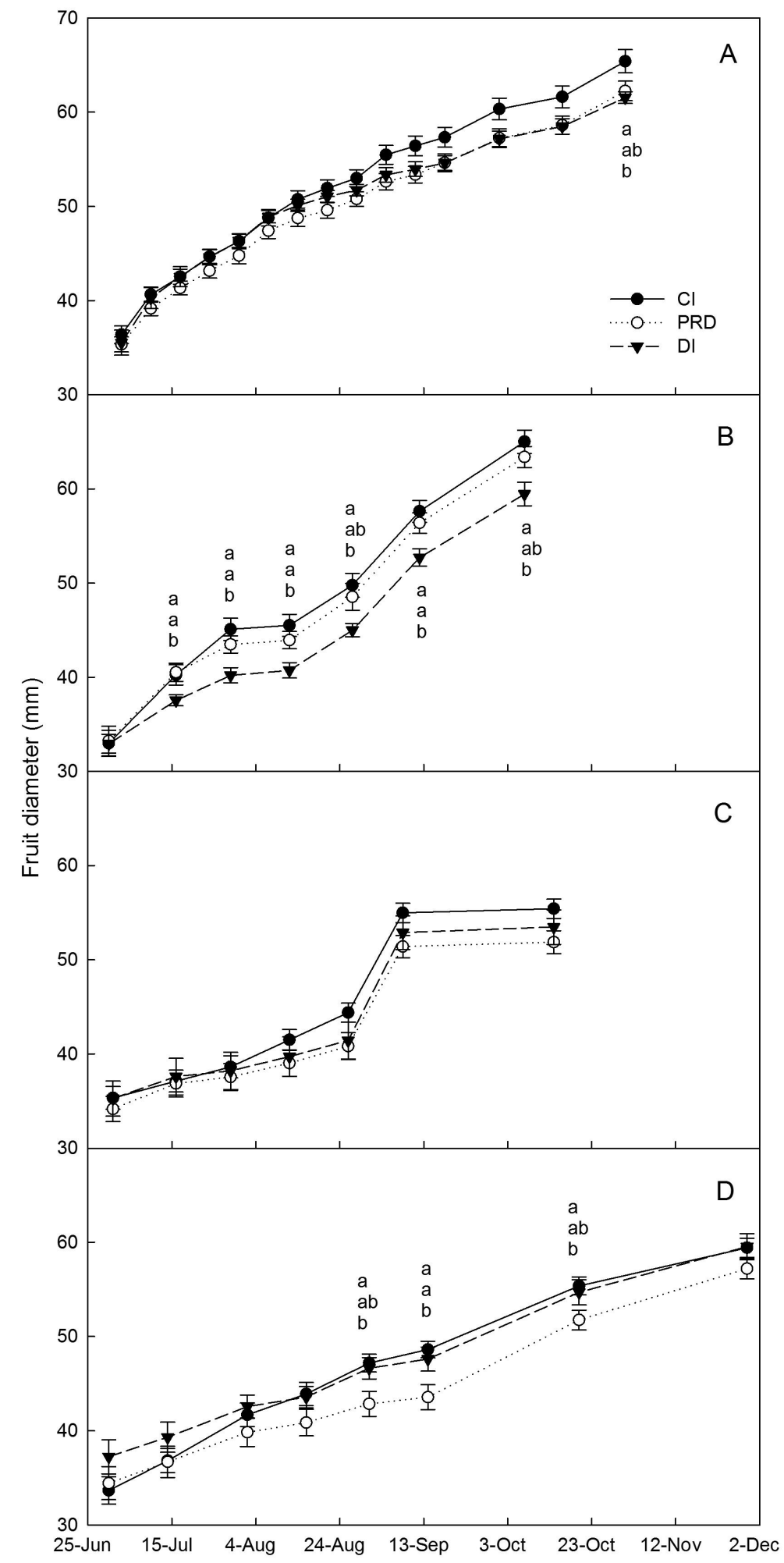

Fig. 8 Fruit diameter of 'Valencia' orange trees under conventional irrigation (CI), partial rootzone drying (PRD), and continuous deficit irrigation (DI) in 2007 (A), 2008 (B), 2009 (C), and 2011 (D). Error bars represent standard errors of the means. When present, different letters indicate significant differences among irrigation treatments for a specific date (Tukey's test, $\mathrm{P}<0.05$ ). 


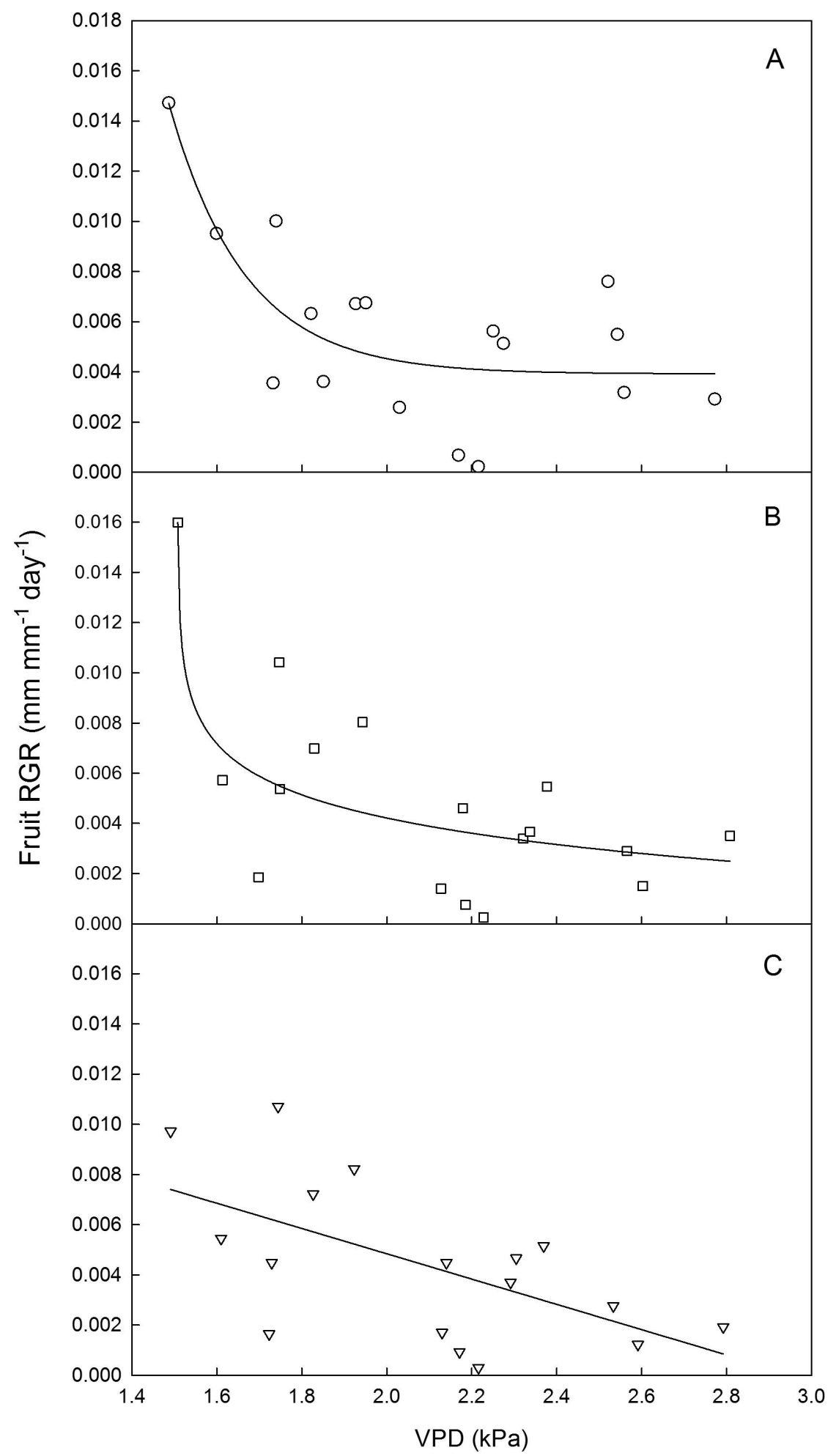

Fig. 9 Relationships between vapor pressure deficit (VPD) and fruit relative growth rate (RGR) in 'Valencia' orange trees under conventional irrigation (A, CI), partial rootzone drying $(B, P R D)$, and continuous deficit irrigation $(\mathrm{C}, \mathrm{DI})$. Data points are averages for each sampling date and irrigation treatment during the five years of trial. In CI, RGR $=0.004+44.2 \exp (-5.60 \mathrm{VPD}), \mathrm{R}^{2}=0.596, \mathrm{P}=$ 0.002 ; in PRD, RGR $=0.003-0.002 \mathrm{Ln}|(\mathrm{VPD}-1.51)|, \mathrm{R}^{2}=0.629, \mathrm{P}=0.001$; in DI, $\mathrm{RGR}=0.015-$ $0.005 \mathrm{VPD}, \mathrm{R}^{2}=0.360, \mathrm{P}=0.011$. 